\title{
GLOBAL BANKS AND SYSTEMIC DEBT CRISES ${ }^{\star}$
}

\author{
JUAN M. MORELLI \\ PABLO OTTONELLO \\ DIEGO J. PEREZ \\ New York University \\ University of Michigan \\ New York University
}

January 10, 2019

\begin{abstract}
We study the role of financial intermediaries in the global market for risky external debt. We first provide empirical evidence measuring the effect of global banks' net worth on bond prices of emerging-market economies. We exploit within-borrower bond variation and show that, around the collapse of Lehman Brothers, bonds held by more distressed global banks experienced larger price contractions. We then construct a model of global banks' lending to emerging economies and quantify their role using our empirical estimates and other key data. In the model, banks' net worths affect bond prices by the combination of a form of market segmentation and banks' financial frictions. We show that these banks' exposure to emerging economies is the key to determine their role in propagating shocks. With the current observed exposure, global banks play an important role in transmitting shocks originating in developed economies, accounting for the bulk of the variation of spreads in emerging economies during the recent global financial crisis. Global banks help explain key patterns of debt prices observed in the data, and the evolution of their exposure over the last decades can explain the changing nature of systemic debt crises in emerging economies.
\end{abstract}

Keywords: Financial intermediaries, debt crises, external debt, world economy

*[Click here for latest draft]. Morelli (jm1934@nyu.edu): Department of Economics, NYU Stern School of Business. Ottonello (ottonellopablo@gmail.com): Department of Economics, University of Michigan. Perez (diego.perez@nyu.edu): Department of Economics, NYU. We thank the seminar and conference participants at Barcelona GSE Summer Forum, Bank of International Settlements, University of British Columbia, and the University of Chicago Booth School of Business for useful comments for useful comments. Maria AristizabalRamirez provided excellent research assistance. 


\section{INTRODUCTION}

Debt crises in emerging-market economies are global in nature. They affect multiple economies in a synchronized fashion and compromise the stability of global financial intermediaries. Salient examples of these events include the Latin American debt crises of the 1980s, linked to major U.S. banks; the Russian/East Asian crises in the 1990s, linked to the collapse of the LTCM fund; and the recent global financial crisis, linked to U.S. and European banks, which affected most emerging economies. Based on the recurrent nature of these episodes, a commonly held view in policy circles is that "global banks" (i.e., financial intermediaries operating in the world economy) play an important role in shaping systemic debt crises. However, most academic literature analyses debt crises in isolation (i.e., from the perspective of individual economies), and abstracts from any explicit role of global financial intermediaries.

In this paper, we reassess this long-held view in policy circles by studying the role of global banks in systemic debt crises. We do so by providing new empirical evidence complemented with a framework to study the global nature of these phenomena. Our empirical analysis studies whether well-identified shocks to global banks' net worth affect bond prices in emerging economies. For this, we exploit within-country-sector variation in bond prices during a short window around the Lehman episode and document larger price drops in bonds held by more-affected global banks. We then construct a model of global banks' lending to emerging economies, and quantify their role using our empirical estimates as well as other key data. In the model, the reason banks' net worths affect bond prices is the combination of a form of market segmentation, which prevents the equalization of expected returns across asset classes, and banks' financial frictions, which link the banks' abilities to supply funds to their net worths. We find that these banks' exposure to emerging economies is the key to determine their role in propagating shocks. With the current observed relatively low exposure, global banks play a major role in transmitting shocks originating in developed economies. In fact, we show that the bulk of the variation of spreads in emerging economies during the recent global financial crisis can be explained by negative shocks to risky assets in developed economies that affected global banks' net worths. In addition, we show that global banks help explain key patterns of debt prices, including the large comovement observed within emerging economies and with other risky securities, and that the evolution of banks' exposure over recent decades can explain the changing nature of systemic debt crises in emerging economies.

Our empirical analysis seeks to measure the effect of global banks' net worth on emergingmarket bond prices. The main empirical challenge for this task is that changes in global banks' 
net worths are linked to other factors driving emerging-market default risk. The key idea of our empirical strategy is that bonds of a given country and sector have similar default risk, but are held by different financial intermediaries. We can then identify the effect of global banks' net worth on emerging-market bond prices by relating the average contraction in the net worth of the financial intermediaries holding a particular bond in a narrow window around the Lehman episode to its subsequent price drop. To measure the average contraction in the net worth of the financial intermediaries holding a particular bond, we collect data on the holdings of each financial intermediary of each individual bond, as well as data on the stock price drop of each publicly traded financial intermediary. We document that bonds held by more severely affected banks during this episode experienced more severe price drops in the two subsequent months. The estimated elasticity is quantitatively large: Bonds whose holders suffer a contraction in net worth one standard deviation higher than the mean experienced a price contraction twice as large as that of the average bond.

We then construct a model of global banks' lending to emerging economies, and use the model together with our empirical estimates to analyze their role in systemic debt crises. We model the world economy as composed by a set of heterogeneous emerging economies facing systemic and idiosyncratic income shocks, which borrow from developed economies using risky debt. Global banks intermediate in this international lending process, but face financing frictions linking investments in risky securities to their net worth. The model, while rich enough to be quantified to explain the data, hinges on key forces that can be characterized in a stylized way. Required returns on emerging-economy debt are determined endogenously and include an intermediation premium and a default-risk component. The intermediation premium is determined to equilibrate aggregate supply and demand of funds for risky assets. This way, shocks that contract the supply of funds, like lower realized returns on global banks' investments, increase the intermediation premium. The default premium is determined by borrowers' incentives to default.

One of our model's main takeaways is that the type of role played by global banks crucially depends on their exposure to emerging-market risky debt. On the one hand, when their exposure is high, global banks play a key role amplifying shocks originating in emerging economies, through a feedback effect between the supply of funds and emerging economies' default rates. On the other hand, when the exposure is low, global banks play a key role in transmitting shocks originating in other risky asset classes. 
To quantitatively assess this role we measure this exposure and inform the model with the estimated elasticity from our empirical analysis. We find that, with the current observed exposure (around ten percent of risky assets), global banks mostly play a role in transmitting shocks originating in developed economies. We illustrate the relevance of their role by showing that the bulk of the variation of emerging-market spreads during the global financial crises can be explained by negative shocks in developed economies that affected the net worth of global banks. In addition, global banks can help explain why bond spreads in the data are highly correlated within emerging economies, and also highly correlated with the returns of other risky securities in developed economies, such as U.S. corporate bonds. In our model, an important part of the fluctuations in debt prices are driven by changes in banks' net worth and the aggregate supply of funds, leading to large comovements similar to those observed in the data.

Finally, our global-bank model sheds light on the history of systemic debt crises in emerging economies. For instance, a common narrative of why the Latin American debt crisis of the 1980s was so pronounced, is that U.S. banks had a very large exposure to these economies, and when their default rates increased banks had to significantly contract credit, further affecting the ability of Latin American economies to repay. Our model captures exactly this mechanism, and shows that the dynamics observed in this crisis are what would have been predicted in our quantitative model when global banks' exposure is large. Our model can also explain why, over recent decades, when financial lenders were more diversified in their portfolios, most of the swings in emerging-market debt prices were linked to changes in realized returns of risky securities in developed economies, as illustrated for instance by the 2008 Lehman episode.

\section{Related literature}

Our paper contributes to several strands of the literature. First, to the literature that studies external debt crises and sovereign default. This literature has shown how the dynamics of external borrowing in emerging economies can be linked to frictions in international credit markets (see, for example, Mendoza, 2002, 2010; Bianchi, 2011) and default risk (see, for example, Arellano, 2008; Aguiar and Gopinath, 2006). Motivated by the high synchronization of debt crises, a recent part of this literature has analyzed the role of lenders in the debt market (see, for example, Aguiar et al., 2016; Tourre, 2017; Arellano et al., 2017; Bai et al., 2018). Our paper contributes to this literature by analyzing debt crises from a global perspective and focusing on the role of financial intermediaries in this market. 
Second, our paper contributes to the literature on the history of debt crises (see, for example, Calvo and Mendoza, 1996; Reinhart and Rogoff, 2009; Kaminsky and Reinhart, 1999; Sachs, 1989). A relevant takeaway from this literature is that financial intermediaries play a key role in emerging economies' debt crises. We contribute to this literature by constructing a model of the world economy with global financial intermediaries that allows us to further understand the channels through which global banks can play an important role in these crises.

Third, our paper is related to the literature on international asset prices and the global financial cycle. This literature has documented a large comovement in debt prices across emerging economies (see, for example, Longstaff et al., 2011; Borri and Verdelhan, 2011), and a strong link between international capital flows and lending in emerging economies (see, for example, Gourinchas and Rey, 2007; Devereux and Yetman, 2010; Rey, 2015; Baskaya et al., 2017; Avdjiev et al., 2018). Our paper shows that global banks can play a key role in these patterns. In this sense, our paper is also related to Gabaix and Maggiori (2015), who study the role of global financial intermediaries in asset markets.

Finally, our paper contributes to the literature on the role of financial intermediaries in the macroeconomy (see, for example, Gertler and Karadi, 2011; Gertler and Kiyotaki, 2010). The closest contributions are Gennaioli et al. (2014), Bocola (2016), Brunnermeier et al. (2016), and Perez (2018), which analyze the role of banks as lenders to risky governments. We contribute to this literature by stressing that the same frictions that help understand financial frictions domestically are relevant in the synchronization of global debt crises and debt prices.

The rest of the paper is organized as follows. Section 2 presents the empirical evidence measuring the effect of global banks' net worth on bond prices of emerging-market economies. Section 3 lays out the model. Section 4 discusses the channels through which global banks amplify and transmit shocks in the risky debt market. Section 5 presents the calibration. We perform the main quantitative exercises in Section 6, and conclude in Section 7.

\section{EMPIRICAL EVIDENCE}

In this section, we provide empirical evidence of the effect of global banks' net worth on emerging-market (EM) debt prices. The estimates obtained constitute new evidence for the role of global banks in EM debt prices, and are also helpful to discipline and quantify the aggregate effects of global banks in the debt market in the next sections. 
FiguRE 1. Emerging-Market Bond Spreads and U.S. Banks' Net Worth

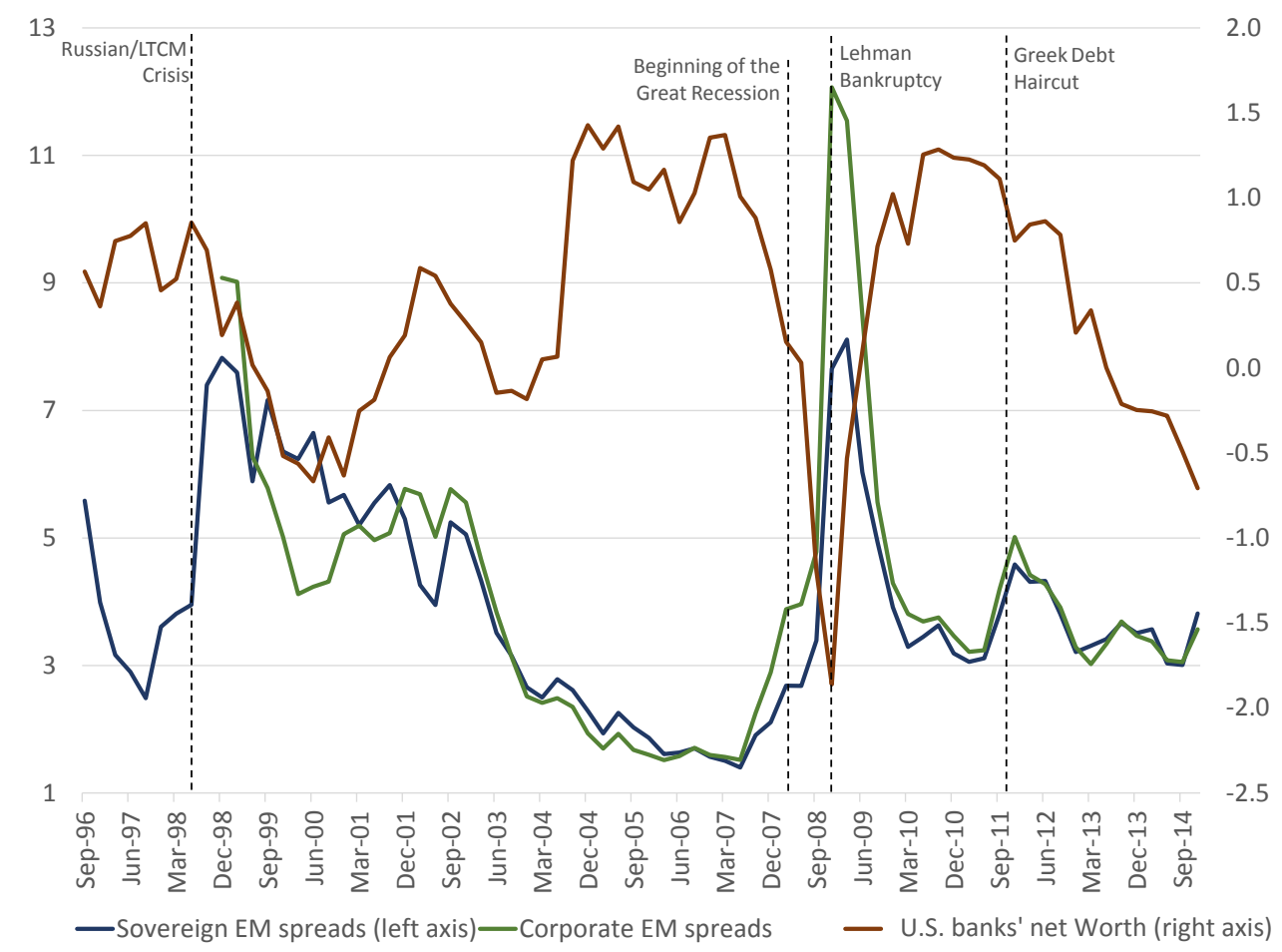

Notes: This figure shows emerging-market sovereign and corporate bond spreads and U.S. banks' net worth. Bond spreads are expressed in percent and are computed as the average spreads across countries included in the JP Morgan's Emerging Markets Bond Index (EMBI; for sovereign spreads) and Corporate Emerging Markets Bond Index (CEMBI; for corporate spreads). Data source: Bloomberg. The net worth of U.S. global banks refers to the difference between the real value of assets and liabilities reported by U.S. chartered depository institutions. Data expressed as percentages relative to a log-linear trend. Data source: Federal Reserve Board, Flow of Funds.

\subsection{Identification}

Figure 1 shows the comovement between EM sovereign and corporate bond spreads and U.S. global banks' net worth over the last decades, characterized by a strong negative correlation of roughly $-55 \%$. Periods of spikes in bond spreads, such at the Russian/East Asian crises of the late 1990s or around the Lehman Brothers bankruptcy in 2008, tend to be periods of declines in U.S. banks' net worth. Our goal is to measure the effect of global banks' net worth on bond prices. The main empirical challenge is that changes in U.S. banks' net worth are correlated with drivers of EM default risk. In addition, changes in net worth are themselves affected by EM returns. 
Our empirical strategy to estimate the effect of global banks' net worth on EM bond prices is to exploit within-country-sector variation in EM bond prices in a narrow window around the Lehman episode. The key idea of this identification strategy is that within an EM countrysector, bonds have similar default risk but different holders. For instance, all foreign-currency sovereign bonds issued by Brazil in foreign markets have the same default risk (e.g., due to cross-default clauses), but are held by different global banks. Moreover, in a narrow window around the Lehman episode, global banks experienced differential changes in their net worth primarily driven by developed-market (DM) factors. We can, therefore, exploit this episode to identify the effect of global banks in bond prices by relating the within-country-sector variation in bond prices to a measure of their holders' net-worth change.

\subsection{Data}

We collect data for sovereign and corporate bonds issued by countries that are part of the EMBI before 2008 and maturing after 2010. We restrict attention to bonds issued in foreign markets and in foreign currency, which are arguably more comparable in terms of their default risk. Our variable of interest is the price of these bonds, which we measure with daily data from Bloomberg and Datastream. For each bond in our sample, we construct a measure of the change in bond holders' average net worth around the Lehman episode, defined as $\Delta n_{i}=\sum_{j=1}^{J} \theta_{i j} \Delta n_{j}$, where $\theta_{i j}$ is the share held by bank $j$ of bond $i$ at 2008.q2, $\Delta n_{j}$ is bank $j$ 's change in net worth around Lehman's bankruptcy (ten days before and three days after September 15, 2008), and $J$ denotes the set of banks with available data. For the variable $\theta_{i j}$, we use data on holdings reported for each bond in Bloomberg. Within these holders, we focus on financial institutions that are publicly traded in developed-market economies, and measure $\Delta n_{j}$ as the log change in its stock price, with data also from Bloomberg and Datastream. Appendix Table A1 details the 50 global banks included in the empirical analysis meeting this selection criteria.

Table 1 provides a set of summary statistics of the data used in the empirical analysis. The first column reports descriptive statistics at the bank level. The average contraction in bank net worth in the narrow window around the Lehman episode is 19\%; the median contraction is $3 \%$. The other three columns report statistics at the bond level. The average share of reported holdings held by global banks, the change in bond holders' average net worth around the Lehman episode, and the change in bond prices. On average, global banks included in our sample held $37 \%$ of reported bond holdings. After weighting global banks by their holdings prior to the Lehman episode, the average contraction in net worth of lenders for the bonds included in our sample is $12 \%$. The standard deviation of this variable is $22 \%$, which suggest 
TABLE 1. Global Banks' Net Worth and Emerging-Market Bond Prices during the Lehman Episode: Summary Statistics

\begin{tabular}{lcccc}
\hline \hline & $\Delta n_{j}$ & $\sum_{j} \theta_{i j}$ & $\Delta n_{i}$ & $\Delta q_{i}$ \\
& Bank level & Bond coverage & Bond level & Bond price \\
\hline Mean & $-19 \%$ & $37 \%$ & $-12 \%$ & $-3 \%$ \\
Median & $-3 \%$ & $34 \%$ & $-8 \%$ & $-2 \%$ \\
Std Deviation & $85 \%$ & $24 \%$ & $22 \%$ & $4 \%$ \\
5th percentile & $-61 \%$ & $5 \%$ & $-33 \%$ & $-12 \%$ \\
95th percentile & $20 \%$ & $88 \%$ & $6 \%$ & $1 \%$ \\
Num. Obs. & 50 & 409 & 409 & 462 \\
\hline \hline
\end{tabular}

Notes: This table shows descriptive statistics for the change in global banks' net worth and bond prices around Lehman's bankruptcy (ten days before and three days after September 15, 2008). The first column $\left(\Delta n_{j}\right)$ reports summary statistics of the log change in global banks' stock prices with reported holdings of EM bonds included in the sample. The second column $\left(\sum_{j} \theta_{i j}\right)$ reports summary statistics of the shares held by these banks for the EM bonds included in the sample. The third column $\left(\Delta n_{i}\right)$ summarizes the change in bond holders' average net worth around the Lehman episode (defined as $\Delta n_{i}=\sum_{j=1}^{J} \theta_{i j} \Delta n_{j}$ ). The fourth column $\left(\Delta q_{i}\right)$ reports log changes in EM bond prices during this episode.

that there is enough variation in lenders' net worth across bonds to exploit in the empirical analysis. Finally, the last column shows that on average EM bond price contracted by $3 \%$ in a narrow window around the Lehman episode. This contraction is relatively small compared to global banks' contraction in net worth, providing support to the view that most of the change in global banks' net worth in this episode was primarily driven by DM factors.

\subsection{Empirical Model and Results}

Our empirical model studies the dynamic effects of global banks' net worth on bond prices using Jorda's 2005 local projections,

$$
\Delta_{h} q_{i k s}=\alpha_{k s}+\beta_{h} \Delta n_{i}+\gamma^{\prime} X_{i}+\varepsilon_{i k s},
$$

where $\Delta_{h} q_{i k}$ denotes the log change in the price of bond $i$ issued by country $k$ in sector $s$ between the Lehman episode and $h$ days after the episode, $\Delta n_{i}$ denotes the change in bond $i$ 's holder's net worth around the Lehman episode (defined in the previous subsection), $\alpha_{k s}$ denotes country-sector fixed effects, $X_{i}$ is a vector of controls at the bond level (including the 
Figure 2. The Effect of Global Banks' Net Worth on Emerging-Market Bond Prices

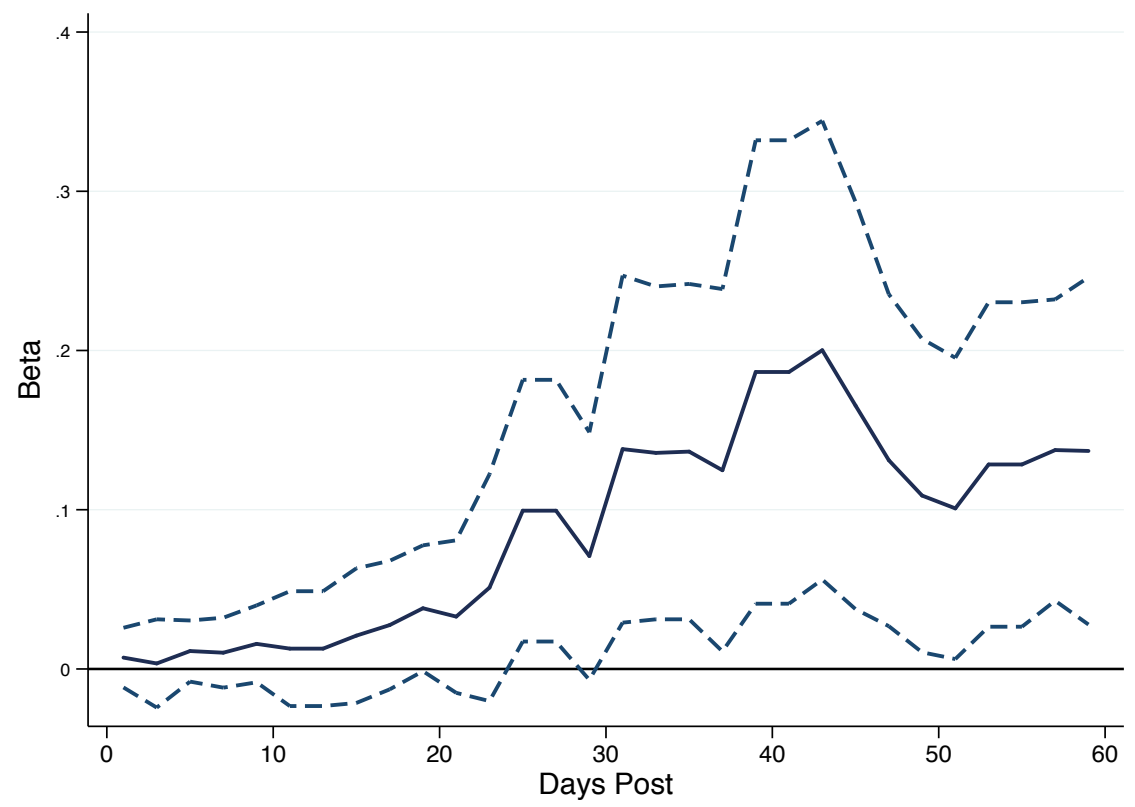

Notes: This figure shows the estimated elasticity of bond prices, $\beta_{h}$, to changes in the holder's net worth at horizon $h$ from estimating the regression 1. Solid lines represent the point estimates of the regression at each horizon, and dotted lines are the 90\%-confidence intervals.

total reported share $\sum_{j=1}^{J} \theta_{i j}$ ), and $\varepsilon_{i k s}$ is a random error term. The coefficient of interest, $\beta_{h}$, measures the elasticity of bond prices to changes in holders' net worth at horizon $h$. We estimate a separate regression for each horizon $h$.

Figure 2 presents the results from estimating (1) at different horizons. Results indicate a positive estimated elasticity, $\beta_{h}$, indicating that bonds whose lender's net worth contracted more during the Lehman episode experienced significantly lower prices in the two months after the episode. The estimated elasticity indicates that a $1 \%$ lower lender net worth translates into $0.1 \%-0.2 \%$ lower prices. To put this estimated coefficient into perspective, note that implies that bonds whose holders suffer a contraction in net worth one standard deviation higher than the mean experienced a price contraction roughly twice as large as that of the average bond during the Lehman episode.

As shall be seen in the next sections, this estimated coefficient can be used to discipline key aspects of the general equilibrium model. For instance, under the assumption that EMs do not arbitrate out price differences across bonds and that the feedback effects from bond prices into bank net worth are small, the estimated elasticity can be interpreted as the price 
effect given a shift in the supply due to changes in net worth. ${ }^{1}$ Under this interpretation, the estimated coefficient can be expressed as the product of the inverse of the supply elasticity and the "portfolio elasticity":

$$
\hat{\beta} \simeq(\underbrace{\frac{\partial \log A_{i}^{s}}{\partial \log q_{i}}}_{\text {supply elasticity }})^{-1} \underbrace{\frac{\partial \log A_{i}^{s}}{\partial \log N_{i}}}_{\text {portfolio elasticity }}
$$

The estimated elasticity is therefore informative about the supply elasticity, which is one of the main elements governing the role played by global banks in the EM debt market.

\section{A Model of the Global Economy}

\subsection{Environment}

The global economy consists of a continuum of DM economies and a continuum of heterogeneous EM economies. Households in these two types of economies differ in their preferences, giving rise to international lending. DM households are risk-neutral and patient, while EM households are risk-averse and impatient.

The key feature of the model is that international lending is mediated by global banks. Households in DMs lend to global banks using a risk-free bond ("deposits"). Global banks, in turn, lend to EMs using risky bonds. Global banks face frictions in their intermediation activity that limit their ability to raise funds from DMs. As alternative investment opportunities, global banks can also invest in risky DM technologies.

Households in EMs receive each period a stochastic endowment of tradable goods, which has a systemic component (common across all EMs) and an idiosyncratic component (whose realizations differ across EMs). EM households lack commitment to repay their debt. We interpret household borrowing in a broad sense, capturing direct international borrowing, sovereign borrowing, or borrowing through other agents (e.g., local banks). Figure 3 graphically represents the global economy.

Time is discrete and infinite. Within each period, the timing is as follows. At the beginning of each period, exogenous variables are realized. EM households choose repayment. Global

\footnotetext{
${ }^{1}$ We consider this a plausible interpretation because (i) EMs did not issue debt or conduct buybacks during this period - see Figure A1 - and (ii), as will be shown in detail in the next section, global banks' EM exposure is relatively small. In the quantitative analysis, we conduct alternative interpretations of this estimate including both demand and net worth channels.
} 
Figure 3. The Global Economy

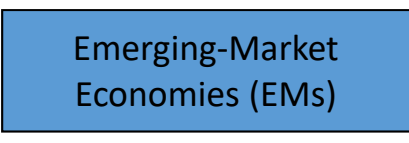

- Risk-averse/impatient

- Borrow without commitment

- Tradable endowment

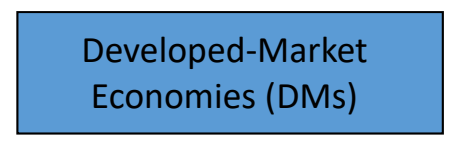

- Risk-neutral/patient

- Save in risk-free bonds

- Tradable endowment + production technology

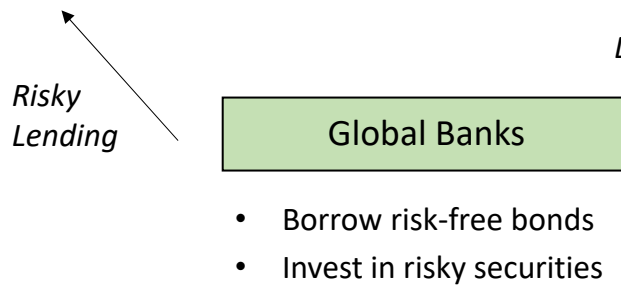

banks choose their portfolio, DM households their savings, and EM households their borrowing. Appendix $\mathrm{C}$ provides details of these state vectors and the recursive representation of the model.

\subsection{Developed Economies}

Households. The representative DM household has preferences described by the lifetime expected utility

$$
\mathbb{E}_{0} \sum_{t=0}^{\infty} \beta_{\mathrm{DM}}^{t} c_{\mathrm{DM} t},
$$

where $c_{\mathrm{DM} t}$ denotes consumption and $\beta_{\mathrm{DM}} \in(0,1)$ the DM household's subjective discount factor.

Each period, households receive an endowment of tradable goods $y_{\mathrm{DM}}$ and time to work $\bar{h}$. They can save in deposits in global banks that pay a return $R_{d t}$ for every unit of deposit in $t+1$. Their sequential budget constraint is given by

$$
c_{\mathrm{DM} t}=y_{\mathrm{DM}}+w_{t} \bar{h}+R_{d t} d_{t}-d_{t+1}+\pi_{t}
$$

where $w_{t}$ denotes wages in period $t, d_{t+1}$ denotes the amount of deposits in $t$ to be repaid in $t+1$, and $\pi_{t}$ denotes net payouts from global banks.

The DM household's problem is to choose state-contingent plans $\left\{c_{\mathrm{DM} t}, d_{t+1}\right\}_{t=0}^{\infty}$ to maximize (12) subject to (3), taking as given prices $\left\{R_{d t}, w_{t}\right\}_{t=0}^{\infty}$ and transfers $\left\{\pi_{t}\right\}_{t=0}^{\infty}$. Household's optimization delivers a constant equilibrium interest rate for deposits, $R_{d t}=\beta_{\mathrm{DM}}^{-1}$. 
Firms. DM economies are also populated by a representative nonfinancial firm, which has access to technologies to produce tradable goods and accumulate capital given, respectively, by

$$
\begin{aligned}
F_{t}\left(k_{t}, h_{t}\right) & =z_{\mathrm{DM} t} k_{t}^{\alpha} h_{t}^{(1-\alpha)}, \\
k_{t+1} & =(1-\delta) k_{t}+i_{t},
\end{aligned}
$$

with $\alpha, \delta \in(0,1)$, where $k_{t}$ is the stock of capital at the beginning of period $t, h_{t}$ is hours of work hired by the firm, $i_{t}$ is investment, and $z_{\mathrm{DM} t}$ is an exogenous productivity process with $z_{\mathrm{DM} t} \in\left[\underline{z}_{\mathrm{DM}}, \bar{z}_{\mathrm{DM}}\right] .^{2}$ Firms are owned by global banks, as we describe later.

\subsection{Global Banks}

Global banks are financial firms owned by DM households. Their objective is to maximize the lifetime discounted dividends transferred to DM households,

$$
\max \mathbb{E}_{t} \sum_{s=0}^{\infty} \beta_{\mathrm{DM}}^{s-t} d i v_{j t+s},
$$

where $d i v_{j t}$ denotes dividend payments of bank $j$ in period $t$. Global banks engage in financial intermediation in the global economy. They can invest in two types of risky securities, claims on nonfinancial firms from DM economies, $a_{\mathrm{DM} j t}$, and bonds issued by EM economies, $\left\{a_{\mathrm{EM} j t}^{i}\right\}_{i \in \mathcal{I}_{t}}$, where $i$ indexes a particular EM economy and $\mathcal{I}_{t}$ the set of EM economies that issue bonds in period $t$. The amount of final goods that the global bank obtains from these investments, or net worth, is given by

$$
n_{j t}=\int_{i \in \mathcal{I}_{t-1}} R_{\mathrm{EM} t}^{i} a_{\mathrm{EM} j t-1}^{i} \mathrm{~d} i+R_{\mathrm{DM}} a_{\mathrm{DM} j t-1}-R_{d} d_{j t-1}
$$

where $\left\{R_{\mathrm{EM} t}^{i}\right\}_{i \in \mathcal{I}_{t-1}}$ is the set of returns of EM bonds in period $t$ and $R_{\mathrm{DM} t}$ is the return of the claims of nonfinancial firms in DM economies in period $t$. Banks use their net worth, as well as risk-free deposits from DM households, to finance investments in risky securities and dividend payments:

$$
n_{j t}+d_{j t}=\int_{i \in \mathcal{I}_{t}} a_{\mathrm{EM} j t}^{i} \mathrm{~d} i+a_{\mathrm{DM} j t}+d i v_{j t}
$$

\footnotetext{
${ }^{2}$ We assume that $\underline{z}_{\mathrm{DM}}$ is such that, in equilibrium, $\alpha \underline{z}_{\mathrm{DM}} K_{t+1}^{\alpha-1}+(1-\delta)>R_{d}$, where $K_{t}$ is the aggregate capital stock at the beginning of period $t$. This assumption ensures that global banks' financial constraints (discussed in detailed in the next subsection) are always binding, which makes their problem computationally more tractable.
} 
Banks face frictions to finance their investments. First, they face a borrowing constraint, linking their risky investment to their net worth,

$$
\kappa\left(\int_{i \in \mathcal{I}_{t}} a_{\mathrm{EM} t}^{i} \mathrm{~d} i+a_{\mathrm{DM} t}\right) \leq n_{t},
$$

where $\kappa>0$. In addition, we assume that banks cannot raise new equity. That is, $d i v_{j t} \geq 0$. Finally, to ensure that banks to not outgrow their financial frictions, we assume that they exit with an exogenous i.i.d. probability $(1-\sigma)$. New banks are endowed with net worth $\bar{n}$, and the total mass of global banks is always fixed at one.

The global bank's problem is to choose state-contingent plans $\left\{\left\{a_{\mathrm{EM} j t}^{i}\right\}, a_{\mathrm{DM} j t}, d_{j t}, \operatorname{div}_{j t} \geq 0\right\}$ to maximize (6) subject to (7) and (9). Appendix C shows the bank's recursive problem. Our formulation gives rise to a problem that is linear in net worth, and whose solution is characterized by constraints (9) and $d i v_{j t} \geq 0$ holding with equality and

$$
\begin{aligned}
R_{\mathrm{EM} i t}^{e} & =R_{\mathrm{DM} t}^{e} \\
R_{\mathrm{DM} t}^{e} & =R_{d t}^{e}+\mu_{t} \kappa
\end{aligned}
$$

for any solution with $a_{i \mathrm{EM}}>0, a_{j \mathrm{EM}}>0$, where $R_{\mathrm{EM} i t}^{e} \equiv \mathbb{E}_{t}\left[v_{t+1} R_{\mathrm{EM} t+1}^{i}\right], R_{\mathrm{DM} t}^{e} \equiv \mathbb{E}_{t}\left[v_{t+1} R_{\mathrm{DM} t+1}\right]$, and $R_{d t}^{e} \equiv R_{d} \mathbb{E}_{t}\left[v_{t+1}\right], v_{t}$ is the marginal value of net worth for global banks, and $\sigma \beta_{\mathrm{DM}} \mu_{t} \geq 0$ is the Lagrange multiplier associated with borrowing constraint (9). Equation (10) implies that the global bank equates expected returns across asset classes, while equation (11) implies that the borrowing constraint prevents global banks from equalizing expected returns between risky and risk-free assets.

\subsection{Emerging Economies}

Each emerging economy is populated by a mass one of identical households with preferences described by the lifetime utility

$$
\mathbb{E}_{0} \sum_{t=0}^{\infty} \beta_{\mathrm{EM}}^{t} u\left(c_{i t}\right)
$$

where $u(\cdot)$ is increasing and concave, $c_{i t}$ denotes consumption of the representative household of EM $i$ in period $t$ and $\beta_{\mathrm{EM}} \in\left(0, \beta_{\mathrm{DM}}\right)$ is the subjective discount factor of EM households. Each period, EM households receive a stochastic endowment of tradable goods, with a systemic component $y_{\mathrm{EM}}$, common across all EMs, and an idiosyncratic component $z_{i t}$. After observing the realization of their endowment, households choose to repay debt they inherited from the previous period $\left(\iota_{i t}=0\right)$ or to default $\left(\iota_{i t}=1\right)$. Defaulting households loose access to external credit markets and reenter when the random variable $\zeta_{i t} \sim \operatorname{Bernoulli}(\theta)$ equals one. 
This implies that households remain in financial autarky for a stochastic number of periods. Households that repay their previous promises can issue one-period bonds, whose promised payments are not state contingent, facing a bond-price schedule $q_{i t}\left(b_{i t+1}\right)$ that depends on the EM characteristics and borrowing choices. Their sequential budget constraint is

$$
c_{i t}=y_{\mathrm{EM} t}+z_{i t}+q_{i t}\left(b_{i t+1}\right) b_{i t+1}-b_{i t} .
$$

Households excluded from global capital markets simply consume their endowments

$$
c_{i t}=\mathcal{H}\left(y_{\mathrm{EM} t}+z_{i t}\right)
$$

where $\mathcal{H}(x) \leq x$ captures the output losses associated with the default decision. The household problem in recursive form is detailed in Appendix C.

In partial equilibrium, this problem is equivalent to a standard borrowing problem in a small open economy with default. However, the bond-price schedule faced by EM households in this economy will be affected by the interaction between global banks, the distribution of debt positions across EMs, and systemic variables introduced by our framework.

\subsection{Equilibrium}

Definition 1 defines a competitive equilibrium in the global economy.

Definition 1. Given global banks' initial portfolios $\left(\left(a_{\mathrm{EM} j-1}^{i}\right)_{i \in[0,1]}, a_{\text {рм } j-1}, d_{j,-1}\right)_{j \in[0,1]}$, EM households' initial debt positions $\left(b_{i t}\right)_{i \in[0,1]}$, and state-contingent processes $\left\{z_{\mathrm{DM}}, y_{\mathrm{EM} t},\left(z_{i t}, \zeta_{i t}\right)_{i \in[0,1]}\right\}$, a competitive equilibrium in the global economy is a sequence of prices $\left\{w_{t},\left(q_{i t}\left(b_{t+1}\right)\right)_{i \in(0,1)}\right\}_{t=0}^{\infty}$ and allocations for DM households $\left\{c_{\mathrm{DM} t}, d_{t+1}\right\}_{t=0}^{\infty}$, nonfinancial firms $\left\{h_{t}, k_{t+1}\right\}_{t=0}^{\infty}$, global banks $\left\{\left(\left(a_{\mathrm{EM} j t}^{i}\right)_{i \in[0,1]}, a_{\mathrm{DM} j t}, d_{j, t}\right)_{j \in[0,1]}\right\}_{t=0}^{\infty}$, and EM households $\left\{\left(c_{i t}, b_{i t+1}, \iota_{i t}\right)_{i \in[0,1]}\right\}_{t=0}^{\infty}$ such that

i. Allocations solve agents problems at the equilibrium prices,

ii. Assets and labor markets clear.

In equilibrium, asset markets clearing implies that global bank's investment in each risky security traded in the global economy equalizes the amount of that type of securities issued:

$$
\begin{aligned}
& A_{\mathrm{EM} i t} \equiv \int_{j \in[0,1]} a_{\mathrm{EM} j t}^{i} \mathrm{~d} j=b_{i t+1}, \\
& A_{\mathrm{DM} t} \equiv \int_{j \in[0,1]} a_{\mathrm{DM} j t} \mathrm{~d} j=k_{t+1} .
\end{aligned}
$$

The return for each type of security is given by $R_{\mathrm{EM} i t+1}=\frac{\iota_{i t+1}}{q_{i t}\left(b_{i t+1}\right)}$ and $R_{\mathrm{DM} t+1}=z_{\mathrm{DM} t} \alpha A_{\mathrm{DM} t}^{\alpha-1}+$ $(1-\delta)$. 


\section{Global Supply and Demand for EM Debt}

We discuss theoretically the channels through which global banks affect EM debt. For this, we consider an economy without aggregate uncertainty, and study the effects of fully unanticipated aggregate shocks, with perfect foresight transitional dynamics back to steady state. We incorporate a stochastic structure for aggregate shocks in the next section, where we analyze the quantitative version of our model.

\subsection{Equilibrium in the Risky-Debt Market}

We begin by constructing a simple demand-supply scheme representing the equilibrium in the global debt market. On the lender side, combining optimal portfolio choices and borrowing constrains holding with equality across banks, we obtain a positive relationship between EMs' required returns and aggregate funds invested in EMs, which we label aggregate supply:

$$
A_{\mathrm{EM} t}=\mathcal{A}_{t}^{s}\left(R_{\mathrm{EM} t}^{e}, N_{t}\right) \equiv \frac{1}{\kappa} N_{t}-\left\{\left[R_{\mathrm{DM} t}^{e}-(1-\delta)\right]\left(\alpha z_{\mathrm{DM} t}\right)^{-1}\right\}^{\frac{1}{\alpha-1}},
$$

where $N_{t} \equiv \int_{j \in[0,1]} n_{j t} \mathrm{~d} j$ denotes the aggregate net worth of banks engaged in lending in period

$t, \frac{\partial A_{t}^{s}}{\partial R_{\mathrm{EM} t}^{e}}>0$ and $\frac{\partial A_{t}^{s}}{\partial N_{t}}>0$. This equilibrium condition represents the fact that when EM returns are high, global banks require also higher returns for DM securities, which occurs with a higher marginal product of capital and a lower aggregate funds allocated to DMs. The aggregate net worth of global banks acts as an aggregate supply shifter: For a given level of EM returns, a higher global-bank net worth leads to more funds invested in EMs.

On the borrower side, aggregating borrowing across EMs and using the definition of returns, we obtain a relationship between required return and borrowing in EMs, which we label aggregate demand:

$$
A_{\mathrm{EM} t}=\mathcal{A}_{t}^{d}\left(R_{\mathrm{EM} t}^{e}\right)=\int_{i \in \mathcal{I}_{t}} \frac{1}{R_{t}^{e}} \iota_{i t+1} b_{i t+1} \mathrm{~d} i .
$$

The slope of aggregate demand is given by $\frac{\partial \mathcal{A}_{t}^{d}\left(R_{\mathrm{EM} t}^{e}\right)}{\partial R_{\mathrm{EMM} t}^{e}}=-\frac{1}{R_{t}^{e}} l_{i t+1} b_{i t+1}+\frac{1}{R_{t}^{e}} \partial \frac{\partial \iota_{t+1} b_{t+1}}{\partial R_{t}^{e}}$. The first term of this expression is negative, reflecting that higher required returns are associated with lower debt prices and less borrowing for given repayments. The second term reflects the effect of required return on the next period's repayment choices. Although this term cannot be signed analytically, we focus here on a case in which it is negative, as it will be in our quantitative model, reflecting that higher required return reduces borrowing and makes repayments less likely.

Figure 4 depicts the equilibrium aggregate borrowing and required returns as the intersection between aggregate demand and supply of funds, for given levels of global banks' net worth. 
Figure 4. The Global Debt Market Equilibrium
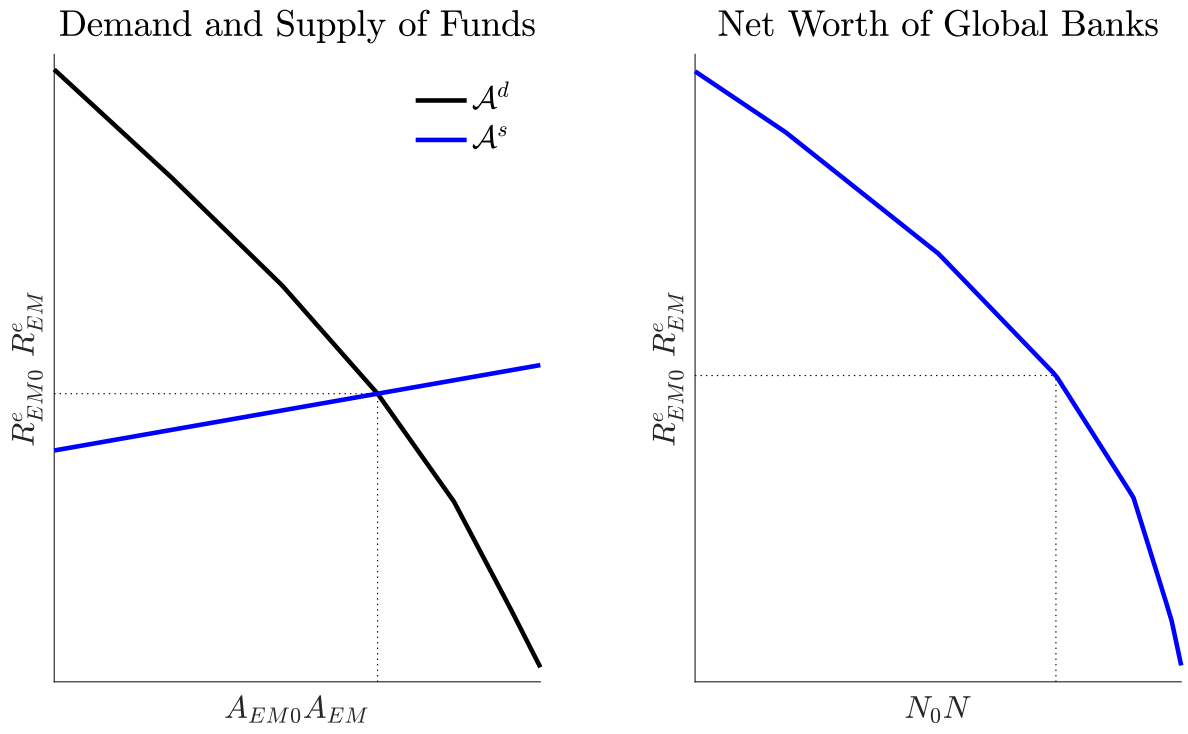

Net worth, however, is also endogenous in this system, as required returns affect borrowers' repayments and realized returns. To obtain this relationship, we integrate the evolution of net worth (7) across banks:

$$
N_{t}=(1-\sigma) \int_{i \in \mathcal{I}_{t-1}} \iota_{i t} A_{\mathrm{EM} i t-1} \mathrm{~d} i+R_{\mathrm{DM} t} A_{\mathrm{DM} t-1}-R_{d} D_{t-1}+\bar{n} .
$$

Given previous-period investments $\left\{\left(A_{\mathrm{Eм} i t-1}\right)_{i \in[0,1]}, A_{\mathrm{DM} t-1}, D_{t-1}\right\}$, the slope of net worth with respect to required returns is given by $\frac{\partial N_{t}}{\partial R_{\mathrm{EM} t}^{e}}=\int_{i \in \mathcal{I}_{t-1}} \frac{\partial \iota_{i t}}{\partial R_{\mathrm{EM} t}^{e}} A_{\mathrm{EM} i t-1} \mathrm{~d} i$. We focus on the case in which this slope is negative, as it will be in our quantitative model, reflecting that higher required returns decrease the value of repayment and leads to more default in EMs (Figure 4, right panel). Together, aggregate supply, aggregate demand, and the evolution of net worth constitute a system of three equations determining aggregate EM borrowing, $A_{\mathrm{Em} t}$, required returns, $R_{\mathrm{EM} t}^{e}$, and global banks' aggregate net worth, $N_{t}$.

\subsection{Aggregate Shocks}

We now use our equilibrium scheme to analyze global banks' role in propagating aggregate shocks. First, consider the effect of an unexpected negative shock to the return of the DM security. This shock affects global banks' net worth and, through this channel, the aggregate supply of funds (see equations (15) and (17)). The initial effect of this shock is represented in Figure 5 as a shift of the net-worth and aggregate-supply curves, indicating lower net worth and lower supply of funds for any given level of EM required returns, leading to an increase in EM required returns. In addition to this initial effect of the shock, there is an amplification 
Figure 5. Aggregate Shocks and Global Debt Market Equilibrium

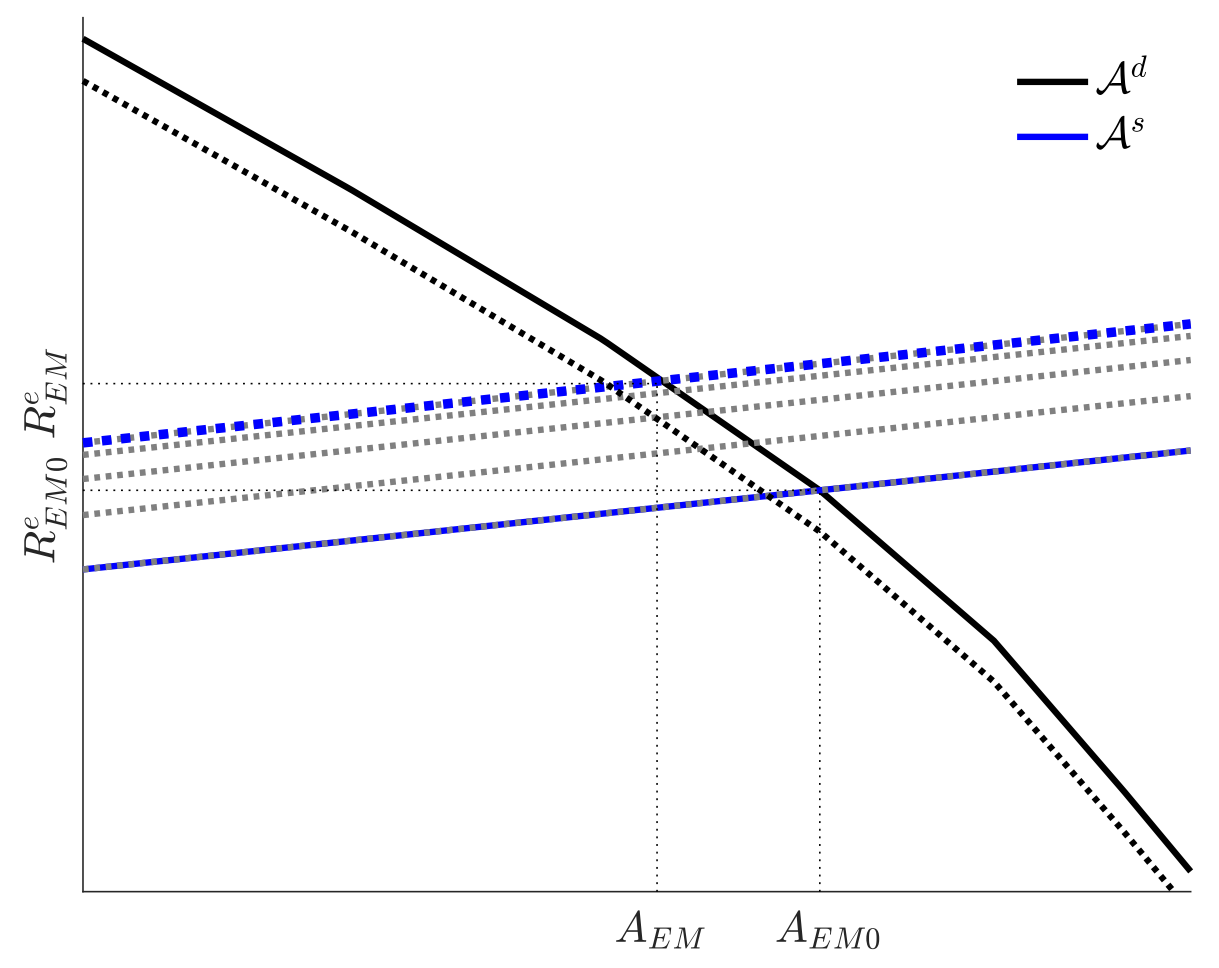

effect that operates through global banks' net worth: Higher required EM returns lead to more EM economies to default, further contracting bank's net worth and the aggregate supply of funds and further increasing EM required returns.

Through a similar mechanism, global banks also amplify systemic shocks originating in EMs. For this, consider now the effect of an unexpected negative shock to systemic EM income. The negative income shock leads more EM economies to default, affecting banks' net worth and the supply of funds in a fashion similar to that analyzed above for the shock to the realized return of DM securities. The negative income shock also affects funds demand. In Figure 5, this is represented as a downward shift in the aggregate demand of funds, as typically occurs in models of risky external borrowing. If the increase in required returns driven by the contraction in aggregate supply is not fully offset by a weaker demand, global banks trigger the amplification through net worth explained below. The amplification through global banks is a key difference between systemic and idiosyncratic EM income shocks. When income shocks are idiosyncratic, they do not affect global banks' net worth and have a smaller effect on debt prices. 


\section{Quantitative Analysis}

In this section, we calibrate the model to match the salient features of global banks and the EM risky-debt market. Importantly, the calibration is informed by the empirical results from Section 2. We then use our quantified model to assess the relevance of global banks as lenders to emerging economies.

\subsection{Calibration}

One period corresponds to one year. The EM households' period utility function is

$$
u(c)=\frac{c^{1-\gamma}}{1-\gamma}
$$

The EM households' endowment processes are

$$
\begin{aligned}
\ln y_{\mathrm{EM} t} & =\rho_{y_{\mathrm{EM}}} \ln y_{\mathrm{EM} t-1}+\sigma \epsilon_{\mathrm{EM} t}, \quad \epsilon_{\mathrm{EM} t} \sim N(0,1), \\
\ln z_{i, t} & =\rho_{z_{i}} \ln z_{i, t-1}+\sigma \epsilon_{i, t}, \quad \epsilon_{i, t} \sim N(0,1) .
\end{aligned}
$$

Similarly, the productivity process of DM firms is

$$
\ln z_{\mathrm{DM} t}=\left(1-\rho_{z_{i}}\right) \mu_{z_{\mathrm{DM}}}+\rho_{z_{i}} \ln z_{\mathrm{DM} t-1}+\sigma \epsilon_{\mathrm{DM} t}, \quad \epsilon_{\mathrm{DM} t} \sim N(0,1)
$$

Finally, the output net of default costs is parametrized by

$$
\mathcal{H}(y)=y\left(1-d_{0} y^{d_{1}}\right)
$$

where $d_{0}, d_{1} \geq 0$. This functional form delivers higher nonlinear default costs for higher values of $y$ (Arellano, 2008; Chatterjee and Eyigungor, 2012).

The model calibration features one set of parameters we set exogenously and another set we calibrate to match relevant moments. We stress the role of two key parameters $(\alpha$ and $\left.\mu_{z_{\mathrm{DM}}}\right)$ that are relevant in determining global banks' role in the EM risky-debt market. We first describe the set of predetermined parameters (Table 2, top). We follow the literature on quantitative macroeconomic models to set values for the exogenous parameters. The probability of reentering credit markets is $\theta=0.25$, so the average exclusion period is of 4 years, in line with empirical evidence (Gelos et al., 2011; Dias and Richmond, 2008). The parameters of the EM households' endowment process are estimated using data on output for the sample of countries analyzed in Section 2. We restrict the systemic and idiosyncratic components of output to have the same stochastic process: $\rho_{y_{\mathrm{EM}}}=\rho_{z_{\mathrm{EM}}}$ and $\sigma_{y_{\mathrm{EM}}}=\sigma_{z_{\mathrm{EM}}}$. This parametric restriction helps us study the differential effects of shocks that arise from endogenous amplification rather than from different stochastic processes. 
TABle 2. Model Calibration

\begin{tabular}{clc}
\hline \hline Parameter & \multicolumn{1}{c}{ Description } & Value \\
\hline Exogenous Parameters & \multicolumn{1}{c}{ risk aversion } & 2.00 \\
$\gamma$ & re-entry probability & 0.25 \\
$\theta$ & systemic endowment autocorrelation & 0.66 \\
$\rho_{y_{\mathrm{EM}}}$ & systemic endowment shock volatility & 0.048 \\
$\sigma_{y_{\mathrm{EM}}}$ & idiosyncratic endowment autocorrelation & 0.66 \\
$\rho_{z_{\mathrm{EM}}}$ & idiosyncratic endowment shock volatility & 0.048 \\
$\sigma_{z_{\mathrm{EM}}}$ & discount rate of DM & 0.98 \\
$\beta_{\mathrm{DM}}$ & share of capital & 0.23 \\
$\alpha$ & depreciation & 0.08 \\
$\delta$ & leverage ratio & 0.10 \\
$\kappa$ & & \\
$\beta_{\beta_{\mathrm{EM}}}$ & discount rate of EMs & 0.85 \\
$d_{0}$ & default cost - level & 0.05 \\
$d_{1}$ & default cost - curvature & 1.50 \\
$\sigma$ & bank payout rate & 0.42 \\
$\bar{n}$ & inflow of net worth & 0.10 \\
$\mathbb{E} z_{\mathrm{DM}}$ & unconditional mean of DM shock & 0.37 \\
$\sigma_{z_{\mathrm{DM}}}$ & volatility of DM shock & 0.15 \\
\hline \hline & autocorrelation of DM shock & 0.07 \\
\hline \hline
\end{tabular}

The remaining predetermined parameters $(\kappa$ and $\alpha$ ) directly influence moments associated with global banks. The parameter on global banks' borrowing constraint, $\kappa=0.1$, ensures that the leverage (defined as the ratio of net worth to assets) is $10 \%$. This leverage ratio is obtained by analyzing the balance sheets of seven major global banks: Banco Santander, HSBC, Citibank, Bank of America, JP Morgan, and Wells Fargo. Figure A2 reports this and other relevant statistics regarding those banks' balance sheets. Finally, the DM firms' share of capital in the production function, $\alpha$, governs the elasticity of EMs' supply of funds. In turn, this elasticity is directly related to the estimated effect of global banks' net worth on bond 
prices from Section 2. ${ }^{3}$ A lower value of $\alpha$ has associated more decreasing returns to scale in the DM firms' aggregate production technology, implying a more inelastic supply of funds for EMs and a larger price effect of drops in banks' net worth. The value of $\alpha=0.23$ implies that the elasticity of EM bond prices to global banks' aggregate net worth is 0.1 , which is our estimated effect from Section 2.

The remaining parameters are calibrated to match specific data moments. Some of these parameters are related EM households $\left(\beta_{\mathrm{EM}}, d_{0}, d_{1}\right)$, others to global banks $(\sigma, \bar{n})$, and others to DM firms $\left(\mu_{z_{\mathrm{DM}}}, d_{0}, d_{1}\right)$. We target moments related to EM debt and default, to global banks, and to other risky assets. Related to EM debt, we target the average level of external debt, the annual rate of default, the average spread, the average correlation of spreads and output, and the average volatility of spreads. ${ }^{4}$ Related to global banks and other risky assets, we target global banks' average exposure to DM risky assets and the volatility and autocorrelation of the DM risky-asset spread. The calibrated values are shown in Table 2. While, in the joint calibration, all moments can be affected by all parameters, we find that the parameters related to EM households mostly affect the EM spread and debt moments, the parameters related to global banks and DM firms affect the price moments of both types of risky assets as well as global banks' portfolio compositions. One important parameter is the average productivity of DM firms, $\mu_{z_{\mathrm{DM}}}$, which directly affects the average return on DM risky debt and, through a general equilibrium effect, the share of banks' assets invested in DM risky assets. When $\mu_{z_{\mathrm{DM}}}$

\footnotetext{
${ }^{3}$ To see this, recall that the aggregate supply is given by (15), which implies that the elasticity of EM bond prices to the aggregate net worth of banks, holding constant the aggregate demand $A_{\mathrm{EM}}$, is

$$
\frac{\partial q_{t}}{\partial N_{t}}=(1-\alpha) \theta_{\mathrm{DM}}\left(\frac{R_{\mathrm{EM} t}^{e}-(1-\delta)}{R_{\mathrm{EM} t}^{e}}\right),
$$

where $\theta_{\mathrm{DM}}=\frac{A_{\mathrm{DM}}}{A_{\mathrm{DM}}+A_{\mathrm{EM}}}$ is the share of DM risky assets on global banks' risky-asset portfolios. The estimated value from Section 2 of this elasticity is 0.1 . Additionally, the observed value of the share of DM risky assets on global banks' risky-asset portfolio is $\theta_{\mathrm{DM}}=0.9$ (see Figure A2) and, given the average required return on EM bonds, we can back out a value of $\alpha=0.23$.

${ }^{4}$ The average level of debt in the data is computed as the average level of external debt of the countries in our sample for the period Sep-96 to Dec-14. The annual rate of default is computed as the average share of EM defaults that occurred in our sample period. The average level and volatility of spreads is computed as the country-time average of sovereign spreads. Its correlation with output is computed as the average correlation of sovereign spreads and the cyclical component of output for each country in our sample. We compute global banks' average exposure to DM risky assets as the exposure to all risky assets that are not EM debt as a fraction of total assets. We use the spreads on the U.S. High Yield corporate bonds to compute the volatility and autocorrelation of the DM risky asset. See Appendix B for data sources and further details in the computation of moments.
} 
TABle 3. Model Calibration

\begin{tabular}{lcc}
\hline \hline \multicolumn{1}{c}{ Target } & Data & Model \\
\hline Average debt & $15.0 \%$ & $13.6 \%$ \\
Average default rate & $0.6 \%$ & $0.1 \%$ \\
Average spread & $395 \mathrm{bp}$ & $330 \mathrm{bp}$ \\
Spreads volatility & $170 \mathrm{bp}$ & $305 \mathrm{bp}$ \\
Correlation of spread and GDP & $-31.0 \%$ & $-30.0 \%$ \\
Portfolio weight on DM & $90.0 \%$ & $92.4 \%$ \\
Volatility of DM Spread & $255 \mathrm{bp}$ & $246 \mathrm{bp}$ \\
Autocorrelation of DM Spread & 0.16 & 0.19 \\
\hline \hline
\end{tabular}

Notes: The first column describes the targeted moments for the model calibration. The second column presents the empirical estimation of the moment. The third column shows the simulated moments from the calibrated model. Average debt is external public sector debt. Yearly default rate is the average of each country's default frequency in the sample. The time span for average debt, default rate, spread-GDP correlation, average spread, and spread volatility is Sep-96 to Dec-14. The portfolio DM weight comes from the 2017 balance sheets of Citibank, HSBC, JPMorgan, Bank of America, Wells Fargo and Banco Santander. The autocorrelation and volatility of DM Spread were computed from U.S. BB corporate bonds at annual frequency for the period 1997 to 2014. Source: World Bank, St Louis FRED, and banks' balance-sheet statements.

is high, the return on DM assets is high, increasing investment by global banks in DM firms, thereby increasing their exposure to DM risky assets. Finally, it is also worth noting that, to match EM levels of debt, we obtain a low calibrated value of $\beta_{\mathrm{EM}}=0.85$, in line with previous literature on quantitative models of sovereign default.

Table 3 shows the data moments and the model moments. Almost all of the moments are well approximated, with the exception of the default frequency, which is lower in the model than in the data. The average spread in the model is composed of a component due to compensation for default risk and another component from the fact EM borrowing proceeds via financial intermediaries that charge a premium.

\subsection{Untargeted Moments}

We evaluate the model's ability to reproduce untargeted moments regarding the synchronization of asset prices. In particular, we ask to what extent is the model able to generate the 
TABle 4. Comovement in Asset Prices: Model and Data

\begin{tabular}{lcc}
\hline \hline & \multicolumn{2}{c}{ Correlation } \\
& Within EMs & High Yield \\
\hline Data & 0.69 & 0.50 \\
Model & 0.77 & 0.69 \\
No Global Banks & 0.60 & N.A. \\
\hline \hline
\end{tabular}

Notes: The correlation variable refers to the correlation of each country's spread with the mean across countries, excluding the treated country. In the model, High Yield refers to the developed-market risky debt. The No Global Banks version excludes financial frictions on global banks, so there is no comovement between emerging-market debt and risky developed-market debt.

high synchronization of debt prices within EM economies and with other risky assets. These exercises help validate the model since matching these data facts was not part of the calibration target. Second, they shed light into global banks' role in the facts regarding debt prices. We compute all exercises for the calibration and for version of the model without global banks. This version of the model corresponds to an economy in which global banks face no financial frictions (i.e. $\kappa=\infty$ in the borrowing constraint) or, equivalently, to an economy in which there is no financial intermediation and DM households lend directly to EM households. To parametrize this economy, we set the same values for the exogenous parameters and recalibrate the remaining parameters to match the same moments as the baseline economy.

We simulate data from both versions of the model and compute the average correlation of individual spreads with the average spread and with required returns from risky DM debt. We compare the model correlations with those of the data. As shown in Table 4, the average correlation of each country's spread with the average EM spread is $69 \%$ in the data. In the baseline model economy, this correlation is $77 \%$, while the correlation is $60 \%$ in model without global banks. The correlation in the model without global banks is lower than that in the data and in the baseline model since there is zero amplification of the systemic component of output and no transmission from shocks originated in risky DM securities. The baseline model is also able to reproduce a large average correlation between individual EM spreads and the required return on risky DM assets. In particular the average correlation in the data (measured by the correlation between EM spreads and U.S. high-yield spread) is $50 \%$ and the one in the model 
is $69 \%$. In the model without global banks, there is no correlation between these asset prices since there is no transmission of shocks.

\section{Systemic Debt Crises and the Role of Global Banks}

In this section, we use the calibrated model to quantitatively assess the role of global banks in the transmission and amplification of shocks in the market of EM risky debt. We first analyze the dynamics of spreads during the global financial crisis through the lens of the model and conclude that global banks played an important role transmitting DM shocks. Second, we analyze whether global banks amplify EM-originated systemic shocks.

\subsection{EM Spread Dynamics during the Global Financial Crisis}

We first use the model to shed light into the dynamics of EM spreads during the global financial crisis. For this, we simulate the model for 1,000,000 periods and identify episodes in which EMs' systemic output fell by the same amount it fell in the data, and in which global banks' aggregate net worth fell as it did in the data. In particular, we look for simulations in which (i) $y_{\text {Ем }}$ fell by $4 \%$ (the peak-to-trough fall of average EM output during 2007-09), and (ii) $z_{\mathrm{DM}}$ fell such that the net worth of aggregate banks falls as it did in the data. The dynamics of global banks' aggregate net worth and EM output, both in the model and in the data, are shown in Figure 6. While the on-impact effects are targeted, the recovery dynamics emerge endogenously from the model and are roughly consistent with those observed in the data. The dynamics of the exogenous shock to $z_{\mathrm{DM}}$ that induce the dynamics of net worth are shown in Figure 8a.

We then compare the dynamics of EM spreads from the model-simulated episodes to the observed dynamics of EM spreads during the global financial crisis. This is shown in Figure 7. The dynamics of spreads in the model track closely those observed in the data, both in terms of the original spike as well as during the recovery. The model slightly overstates the increase in spreads by predicting an increase of around 650 basis points compared to the observed increase of around 550 basis points. The fact that the model is able to reproduce the dynamics of spreads during the global financial crisis provides an additional source of external validation for the model. In the model, spreads increase due to two forces. First, the lower realizations of returns in DM risky assets has a negative impact on global banks' aggregate net worth. With a lower net worth, global banks must reduce their borrowing to maintain the same levels of leverage, and thereby reduce their supply of funds to EMs. Given an aggregate EM demand for funds, this reduces bond prices and increases spreads. Second, a drop in EM output increases 
FiguRE 6. Global Financial Crisis: Exogenous Drivers

\section{(A) Global Banks' Net Worth}

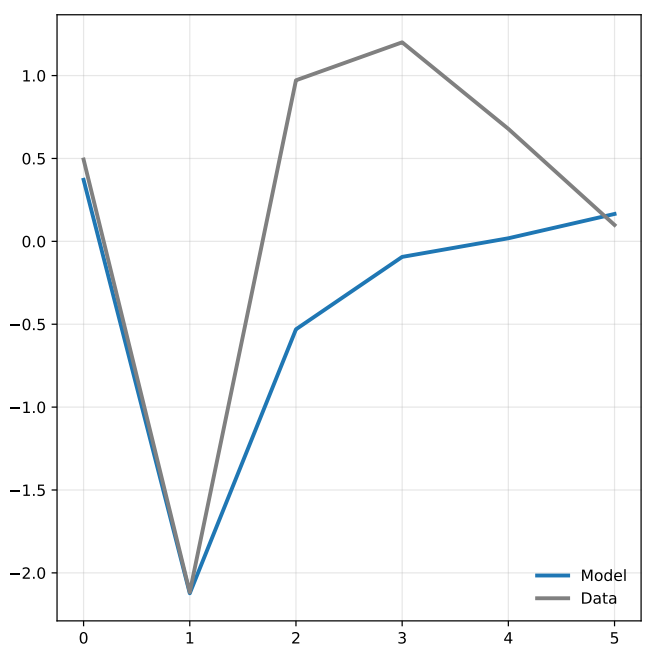

(B) Emerging-Market Output

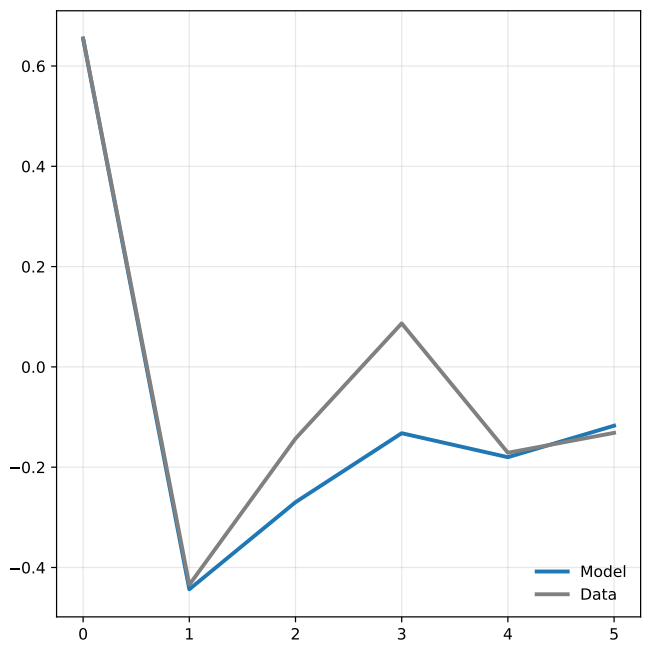

Notes: The left panel shows the observed path of global banks' detrended net worth during the global financial crisis and the model-simulated path of the same variable. The right panel shows the observed average detrended EM output during the global financial crisis and the model-simulated path from the same variable. The observed data corresponds to the average of the countries in our sample. The model-simulated data from both panels show the average path of the variables over episodes within the model simulations in which the net worth and the aggregate systemic output fall by an amount in an interval centered on the observed drop in the data. All variables are in percent deviation from a linear trend.

spreads due to a combination of an increase in default risk and an amplification effect through global banks' net worth.

We then use the model to disentangle the relevance of each of the two shocks in the dynamics of spreads during the global financial crisis. For this, we analyze spread dynamics during episodes in which only $z_{\mathrm{DM}}$ drops and episodes in which only $y_{\mathrm{EM}}$ drops. Results suggest that most of the spread dynamics are due to the DM shock (Figure 8). When we only consider episodes in which returns on DM risky assets fall, the spreads from EMs in the model increase as much as they do in the data. On the other hand, when we consider episodes in which only EM output falls, spreads modestly increase by only 100 basis points. This exercise suggests that most of the observed EM-spread dynamics was due to DM shocks and that global banks played a key role in transmitting those shocks, rather than amplifying EM-originated shocks. 
FiguRE 7. Emerging-Market Spread Dynamics during the Global Financial Crisis: Model and Data

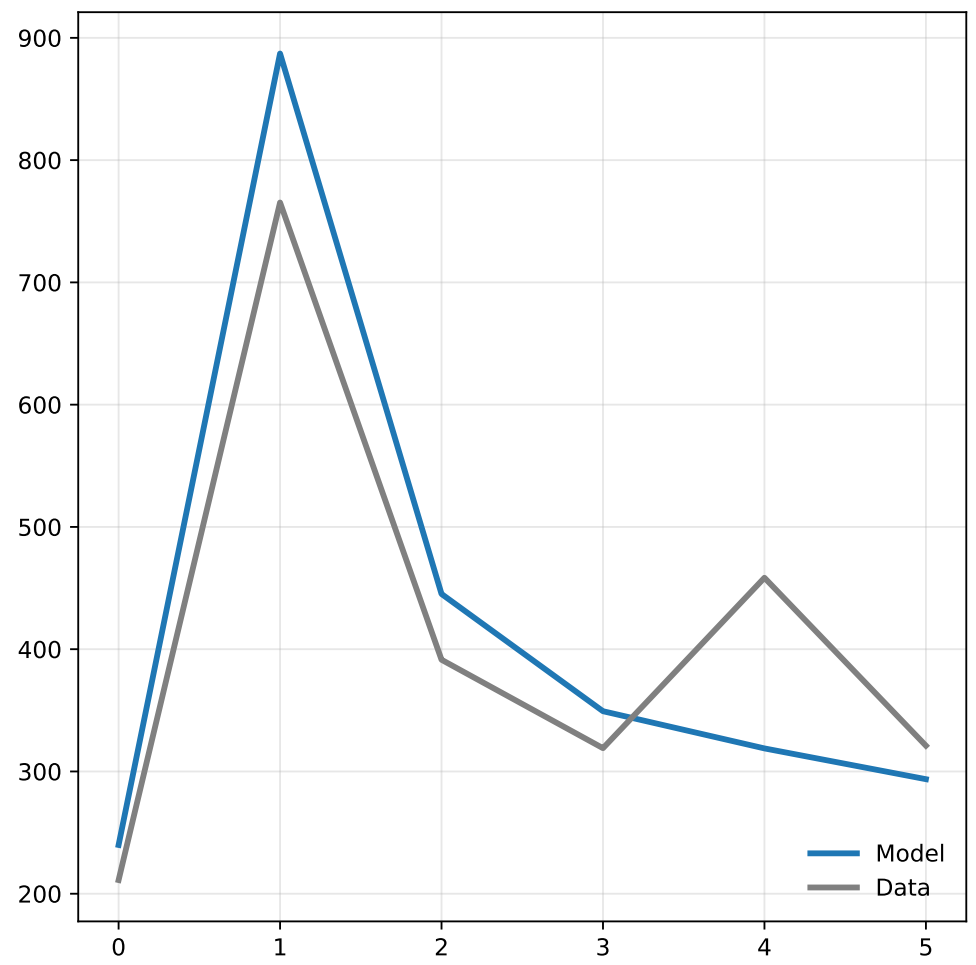

Notes: This figure shows the observed path of emerging-market bond spreads during the global financial crisis and the model-simulated path of the same variable. The observed data is computed as the simple average of spreads of the countries in our sample. The model-simulated data shows the average path of the same variables over episodes within the model simulations in which the net worth and the aggregate systemic output fall by an amount that is in an interval centered on the observed drop in the data. Spreads are annual and are expressed in basis points.

\subsection{Amplification of EM-Originated Shocks}

We analyze the effects of EM households' output shocks on debt prices. In particular, we analyze the impulse-response of equal-magnitude negative shocks to the systemic and idiosyncratic components of output. ${ }^{5}$ The dynamics of the systemic and idiosyncratic output are shown in Figure A5. Both negative shocks have the same negative effect on output since they follow the same stochastic process. The dynamics of spreads under both types of shocks and under both

\footnotetext{
${ }^{5}$ To compute the responses to a shock to the systemic (idiosyncratic) component of output, we simulate the calibrated economies for 1,000,000 periods and identify period in which the systemic (idiosyncratic) component falls by one standard deviation and then trace the dynamics of the variables of interest. We then compute the average response over all identified episodes.
} 
Figure 8. Disentangling Emerging-Market Spread Dynamics

(A) The Role of Shocks in Emerging Markets

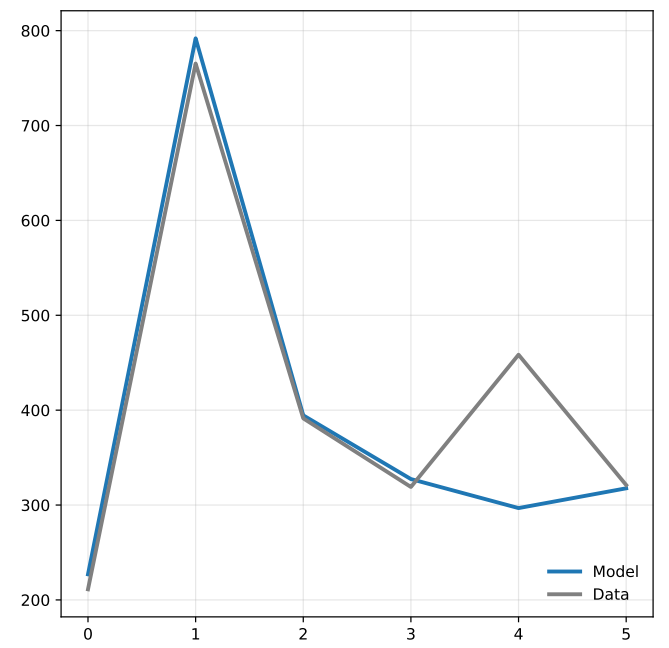

(B) The Role of Shocks in Developed Markets

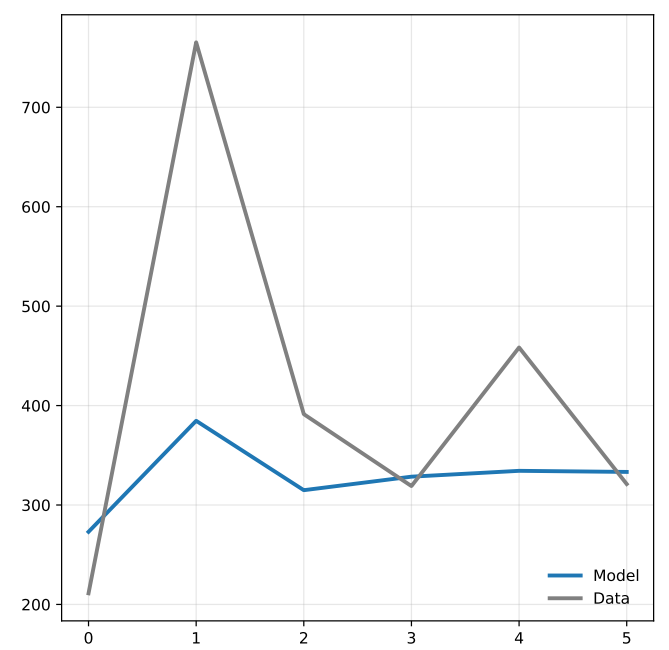

Notes: The left panel shows the observed path of emerging-market bond spreads during the global financial crisis and the model-simulated path of the same variable in episodes in which we only condition global banks' net-worth drop to match the data. The observed data is computed as the simple average of spreads of the countries in our sample. The model-simulated data shows the average path of the same variable over episodes within the model simulations in which the net worth falls by an amount that is in an interval centered on the observed drop in the data. The right panel shows observed spreads with the model-simulated path of spreads in episodes in which we only condition emerging markets' aggregate-output drop to match the data. The modelsimulated data shows the average path of the spreads over episodes within the model simulations in which the emerging-market average output falls by an amount that is in an interval centered in the observed drop in the data. Spreads are annual and expressed in basis points.

calibrations are shown in Figure 9. The left panel shows the spreads' response to an equalmagnitude negative shock to both components of output in the baseline economy. Both shocks trigger an increase in spreads because a lower output increases the value of default relative to the value of repaying and, thus, increases the probability of default. Interestingly, the increase in spreads in response to both shocks is similar in magnitude. This suggests the absence of any global-bank amplification of systemic shocks in the baseline calibration.

We then explore the role of global banks' exposure to EM debt in amplifying systemic output shocks. For this, we consider an alternative calibration in which we recalibrate the value of $\mu_{z_{\mathrm{DM}}}$ to obtain an exposure to EM debt of $20 \%$, double the exposure in the baseline and more in line with the observed exposures in the 1980s (see Table A3). In this economy, we compute the same impulse-response exercise as in the baseline economy. Results are shown in the right 
FiguRE 9. Aggregate Response of Spread to Emerging-Market Output Shocks

(A) Baseline Economy

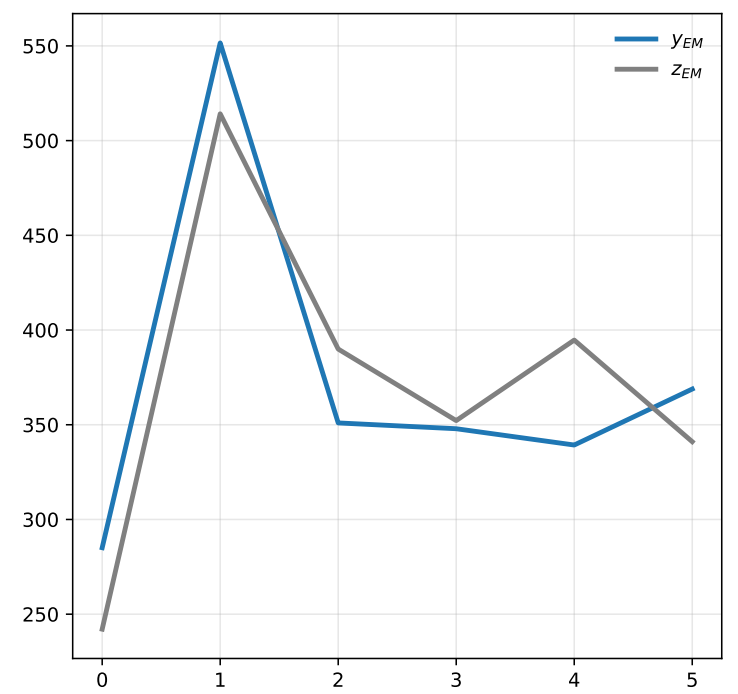

(в) 'High Exposure" Economy

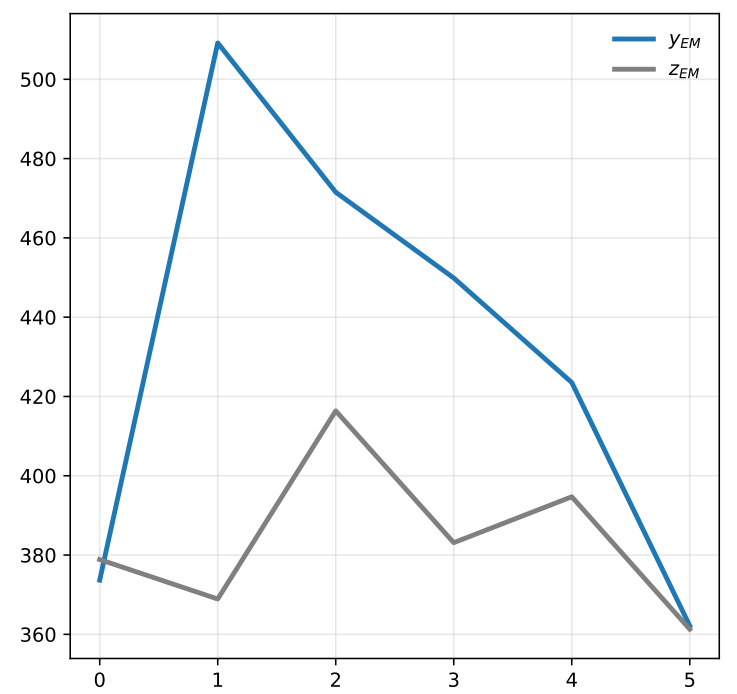

Notes: This figure shows the evolution of spreads in episodes in which the systemic and idiosyncratic components of emerging-market output fall by one standard deviation. The left panel shows the evolution of spreads under the baseline parametrization. The right panel shows a parametrization that exposes global banks to emergingmarket debt of $15 \%$. Spreads are measured in basis points.

panel of Figure 9. In this economy, a negative shock to output can have a differential effect on spreads depending on the nature of the shock. A one-standard-deviation negative shock to the idiosyncratic component of output triggers an increase in the spreads of that country of approximately 50bps. In contrast, a negative shock of the same magnitude to the systemic component of output triggers a spread increase that is three times as large as the response to the idiosyncratic shock. We argue next that this differential response is due to the amplification effect that systemic shocks create by affecting global banks' balance sheets.

\section{Conclusion}

We show that global banks play an important role in the configuration of EMs' systemic debt crises. We first document that they hold a sizable portion of the external debt of emerging economies and that these investments represent a relevant fraction of their total assets.

Based on these observations, we develop a dynamic world-economy model in which external borrowing is intermediated by global banks. We find that banks are relevant in the generation 
and amplification of systemic debt crises. The nature of the global banks' role in systemic debt crises is governed by their exposure to EM debt. When banks are highly exposed, they amplify systemic EM shocks, whereas when their exposure is low, they transmit shocks from other risky assets to the EM debt market. Our model thus formalizes an long-held view in policy circles whereby banks are relevant actors shaping global EM crises. It also sheds light into the channels through which they operate. 


\section{ReFERENCES}

Aguiar, M., S. Chatterjee, H. Cole, and Z. Stangebye (2016): "Quantitative models of sovereign debt crises," in Handbook of Macroeconomics, Elsevier, vol. 2, 1697-1755.

Aguiar, M. And G. Gopinath (2006): "Defaultable Debt, Interest Rates and the Current Account," Journal of International Economics, 69, 64-83.

Algan, Y., O. Allais, And W. J. Den HaAn (2010): "Solving the incomplete markets model with aggregate uncertainty using parameterized cross-sectional distributions," Journal of Economic Dynamics and Control, $34,59-68$.

Algan, Y., O. Allais, W. J. Den HaAn, And P. Rendahl (2014): "Solving and simulating models with heterogeneous agents and aggregate uncertainty," Handbook of Computational Economics, 3, $277-324$.

Arellano, C. (2008): "Default Risk and Income Fluctuations in Emerging Economies," The American Economic Review, 98, 690-712.

Arellano, C., Y. Bai, And S. Lizarazo (2017): "Sovereign risk contagion," Tech. rep., National Bureau of Economic Research.

Avdjiev, S., B. Hardy, S. Kalemli-Ozcan, and L. Serven (2018): "Gross capital flows by banks, corporates, and sovereigns," The World Bank.

Bai, Y., P. J. Kehoe, And F. Perri (2018): "World Financial Cycles," Manuscript.

Baskaya, Y. S., J. di Giovanni, S. Kalemli-Ozcan, and M. F. Ulu (2017): "International spillovers and local credit cycles," NBER Working Paper No. w23149.

BiAnchi, J. (2011): "Overborrowing and systemic externalities in the business cycle," The American Economic Review, 101, 3400-3426.

Bocola, L. (2016): "The pass-through of sovereign risk," Journal of Political Economy, 124, 879-926.

Borri, N. And A. Verdelhan (2011): "Sovereign risk premia," .

Brunnermeier, M. K., L. Garicano, P. R. Lane, M. Pagano, R. Reis, T. Santos, D. Thesmar, S. V. Nieuwerburgh, And D. Vayanos (2016): "The sovereign-bank diabolic loop and ESBies," American Economic Review, 105, 508-12.

Calvo, G. A. And E. G. MendozA (1996): "Mexico's balance-of-payments crisis: a chronicle of a death foretold," Journal of International Economics, 41, 235-264.

Chatterjee, S. And B. Eyigungor (2012): "Maturity, Indebtedness, and Default Risk," The American Economic Review, 102, 2674-2699.

Devereux, M. B. AND J. Yetman (2010): "Leverage constraints and the international transmission of shocks," Journal of Money, Credit and Banking, 42, 71-105.

Dias, D. A. And C. Richmond (2008): "Duration of Capital Market Exclusion: Stylized Facts and Determining Factors," Manuscript.

Gabaix, X. And M. Maggiori (2015): "International liquidity and exchange rate dynamics," The Quarterly Journal of Economics, 130, 1369-1420.

Gelos, R. G., R. Sahay, And G. SAndleris (2011): "Sovereign Borrowing by Developing Countries: What Determines Market Access?" Journal of International Economics, 83, 243-254. 
Gennaioli, N., A. Martín, And S. Rossi (2014): "Sovereign Default, Domestic Banks, and Financial Institutions," The Journal of Finance, 69, 819-866.

Gertler, M. And P. Karadi (2011): "A Model of Unconventional Monetary Policy," Journal of Monetary Economics, 58, 17-34.

Gertler, M. And N. Kiyotaki (2010): "Financial Intermediation and Credit Policy in Business Cycle Analysis," Handbook of Monetary Economics, 3, 547-599.

Gourinchas, P.-O. And H. Rey (2007): "International financial adjustment," Journal of Political Economy, $115,665-703$.

JordA, O. (2005): "Estimation and Inference of Impulse Responses by Local Projections," The American Economic Review, 95, 161-182.

Kaminsky, G. L. And C. M. Reinhart (1999): "The twin crises: the causes of banking and balance-ofpayments problems," American economic review, 89, 473-500.

Krusell, P. And A. A. Smith (1998): "Income and wealth heterogeneity in the macroeconomy," Journal of Political Economy, 106, 867-896.

Longstaff, F. A., J. Pan, L. H. Pedersen, And K. J. Singleton (2011): "How sovereign is sovereign credit risk?" American Economic Journal: Macroeconomics, 3, 75-103.

MendozA, E. G. (2002): "Credit, prices, and crashes: Business cycles with a sudden stop," in Preventing currency crises in Emerging markets, University of Chicago Press, 335-392.

- (2010): "Sudden stops, financial crises, and leverage," American Economic Review, 100, $1941-66$.

Perez, D. (2018): "Sovereign debt, domestic banks and the provision of public liquidity," Manuscript.

Reinhart, C. M. And K. Rogoff (2009): This Time Is Different: Eight Centuries of Financial Folly, Princeton University Press.

Reiter, M. (2009): "Solving heterogeneous-agent models by projection and perturbation," Journal of Economic Dynamics and Control, 33, 649-665.

REY, H. (2015): "Dilemma not trilemma: the global financial cycle and monetary policy independence," NBER Working Paper No. w21162.

SACHS, J. (1989): New approaches to the Latin American debt crisis, 174, Princeton Univ Intl Economics. Tourre, F. (2017): "A Macro-Finance Approach to Sovereign Debt Spreads and Returns," Manuscript. 
Appendix A. Additional Figures and Tables

TABle A1. Main Global Banks Included in the Empirical Analysis of Section

\begin{tabular}{lll}
\hline \hline Aegon NV & Hartford & Royal Bank of Scotland \\
Allianz SE & HSBC & Societe Generale \\
American International Group & Intesa Sanpaolo SpA & Sovereign Bank \\
Ameriprise Financial Inc & JPMorgan & Suntrust Banks \\
BNP Paribas & Keycorp & SVB \\
BNYM & Lehman Brothers & T Rowe Price Group Inc \\
Bank of America & M\&T Bank & TD Bank \\
Bank of Nova Scotia & Merrill Lynch & U.S. Bancorp \\
Barclays Bank & MetLife Inc & UBS \\
Bb\&T & Mitsubishi UFJ & Unionbancal \\
BlackRock Inc & Morgan Stanley & Wachovia \\
CIBC & NN Group NV & Wells Fargo \\
CIT & National City & \\
Citigroup & Nikko Asset Management Co Ltd & \\
Comericarporated & PNC & \\
Credit Suisse & Principal Financial Group Inc & \\
Deutsche Bank & Prudential Financial Inc & \\
Fifth Third Bancorp & Regions & \\
GE Capital & Royal Bank of Canada & \\
\hline \hline
\end{tabular}


FiguRE A1. Emerging-Market Debt Issuance during the Lehman Episode

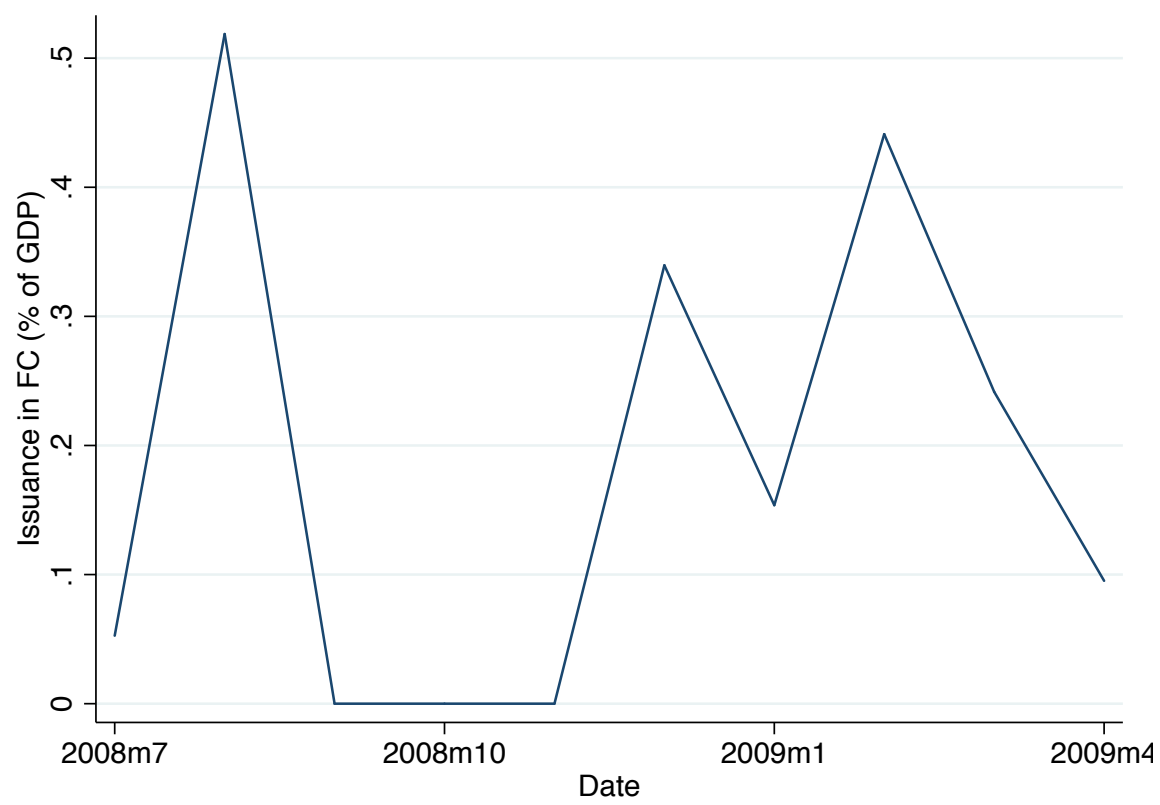

Notes: This figure shows the total amount of new debt issuance in foreign currency by emerging-market economies during the Lehman episode. Issuance is expressed as a function of GDP and averaged across countries.

FiguRE A2. Return Comovements within Emerging Markets and with U.S. Stocks

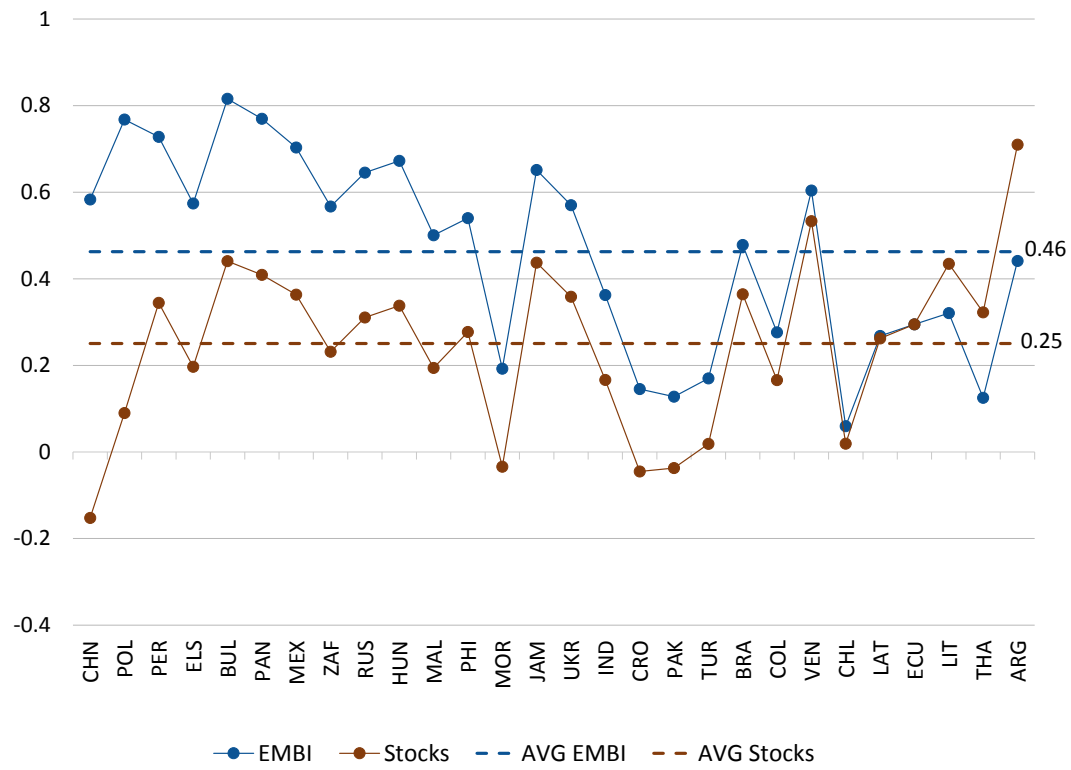

Notes: This figure shows the empirical correlation between a country's sovereign-bond total return and the total return of the U.S. stock market and the simple average of all other countries' sovereign-bond total returns. We take the S\&P500 to represent the U.S. stock market, and the EMBI for the countries sovereign-bond total return. 


\section{FiguRE A3. Systemic Component of Emerging Markets' Output}

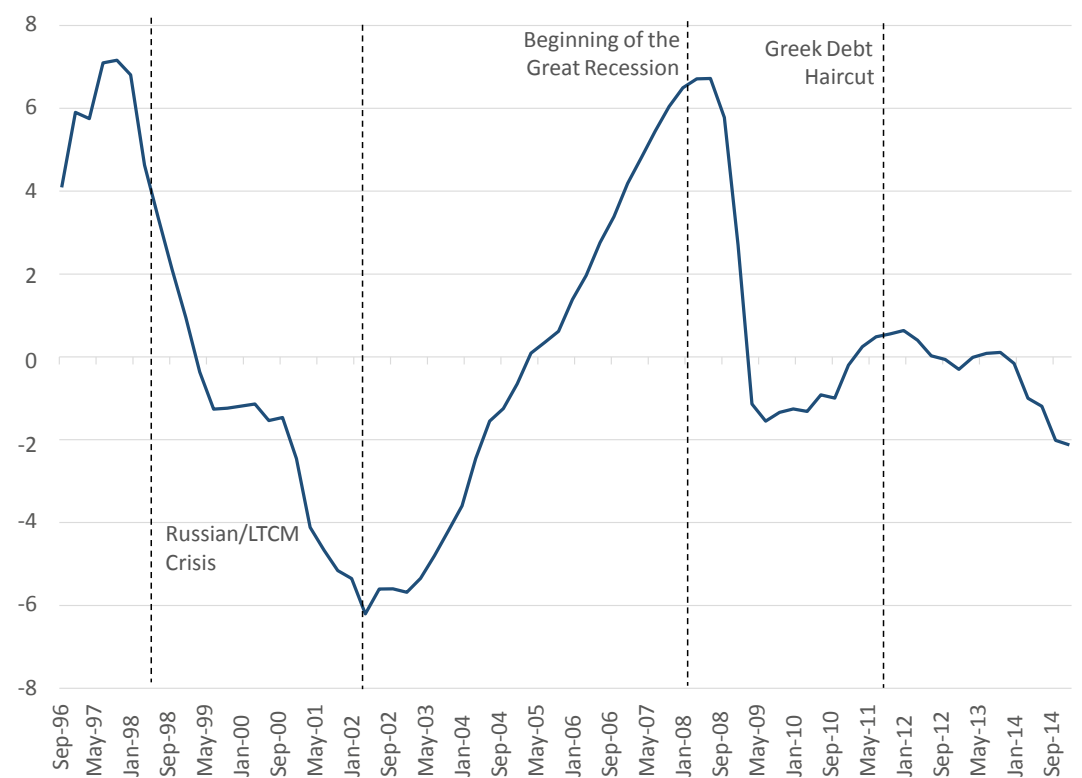

Notes: This figure shows the systemic component of output, defined as the simple average output of all countries in our sample. Output was log-linearly detrended. 
TABLE A2. Major Global Banks' Balance Sheets: 2017

\begin{tabular}{lccc}
\hline \hline Bank & $\begin{array}{c}\text { Share Sovereign } \\
\text { Non-U.S. Debt }\end{array}$ & $\begin{array}{c}\text { Share EM } \\
\text { Debt }\end{array}$ & $\begin{array}{c}\text { Ratio Equity } \\
\text { to Assets }\end{array}$ \\
\hline Santander & $25.5 \%$ & $41 \%$ & $7.4 \%$ \\
HSBC & $24.9 \%$ & $91.2 \%$ & $7.8 \%$ \\
Citi & $21.1 \%$ & & $10.9 \%$ \\
JPMorgan & $12.6 \%$ & & $10.1 \%$ \\
BOFA & $5.2 \%$ & & $11.7 \%$ \\
Wells Fargo & $2 \%$ & $61 \%$ & $10.7 \%$ \\
\hline Average & $15.2 \%$ & $48.3 \%$ & $9.8 \%$ \\
\hline \hline
\end{tabular}

Notes: This table shows selected items of major banks' balance sheets for 2017. The first column shows the share of banks' claims on non-U.S. sovereigns over risky assets. The second column shows what fraction of those claims are on emerging markets. The last column shows the equity-to-assets ratio of each bank. The last row represents the simple average of each variable. Data is publicly available.

TABle A3. Major Global Banks' Balance Sheets: 1980s

\begin{tabular}{rccc}
\hline \hline & 1982 & 1984 & 1986 \\
\hline Debt-to-Capital & & & \\
All Banks & $186.5 \%$ & $156.6 \%$ & $94.8 \%$ \\
Top 9 & $287.7 \%$ & $246.3 \%$ & $153.9 \%$ \\
Capital-to-Assets & $4.8 \%$ & $6.1 \%$ & $7.1 \%$ \\
Debt-to-Assets & & & \\
All Banks & $9.0 \%$ & $9.6 \%$ & $6.7 \%$ \\
Top 9 & $13.8 \%$ & $15.0 \%$ & $10.9 \%$ \\
\hline \hline
\end{tabular}

Notes: This table shows selected items of U.S. commercial banks' balance sheets from the 1980s. Debt-to-Capital refers to the ratio of banks' claims on developing countries to banks' primary capital. The Capital-to-Assets variable is the banks' ratio of primary capital to total assets. These two variables are simple averages across banks. Debt-to-Assets is computed as Debt-to-Capital times Capital-to-Assets, and it represents the ratio of banks' claims on developing countries to banks' total assets. The top nine banks refers to the top nine largest U.S. banks during the 1980s. Source: Sachs (1989) 
Figure A4. Developed-Market Productivity in the Model

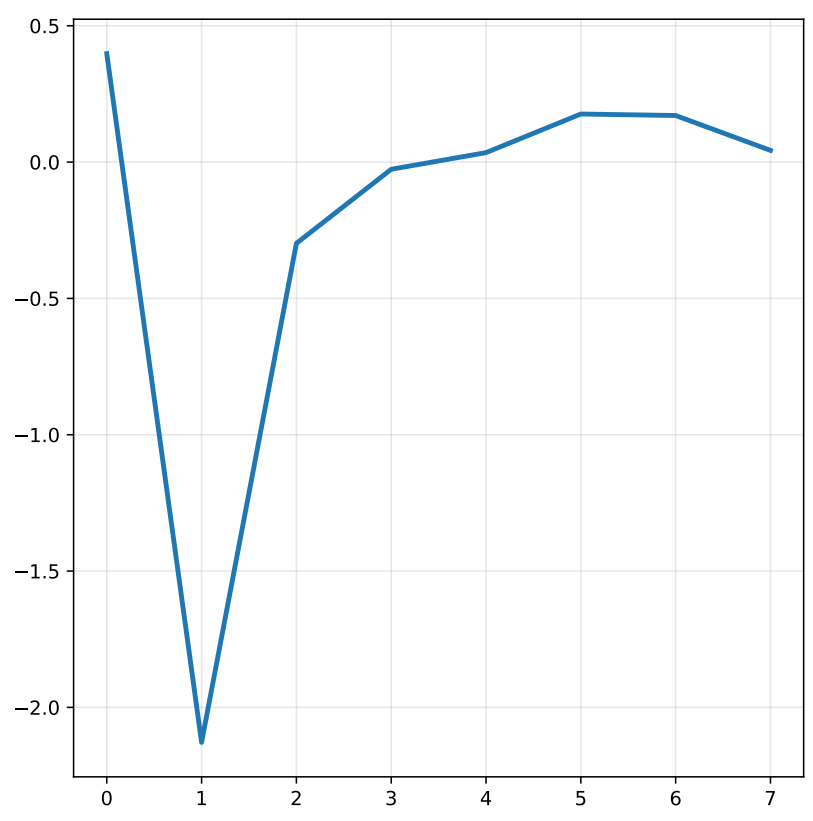

Notes: This figure shows the model-simulated path of developed-market productivity. The model-simulated data shows the average path over episodes within the model simulations in which the net worth and the aggregate systemic output fall by an amount that is in an interval centered in the observed drop in the data. Productivity is measured as percent deviations from a linear trend. 
FiguRE A5. Systemic and Idiosyncratic Output Shocks in the Model

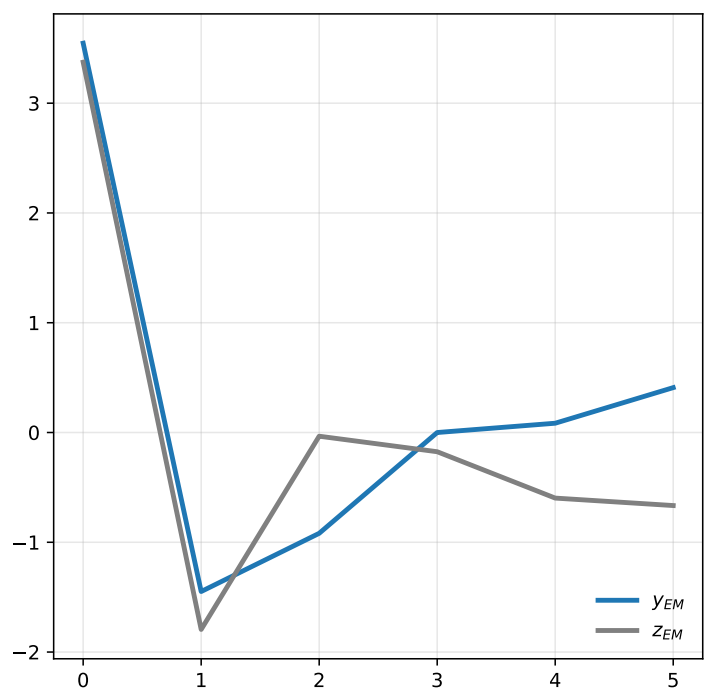

Notes: This figure shows the evolution of the systemic and aggregate components of emerging-market output in model-simulated data. The model-simulated data shows the average path of the variables over episodes within which the variables fall by one standard deviation. Both variables are expressed in percent deviations from a linear trend. 


\section{Appendix B. Data Description}

\section{B.1. Data on Debt Prices and Fundamentals}

Our sample consists of those countries that have had some degree of default risk, as reflected by their credit ratings, and have sufficient data availability. In particular, we consider those countries that: (i) have ever had a credit rating that is below A in the Standard and Poor's Global Ratings scale, and (ii) have at least 10 years of available data on debt prices and output. 28 countries met the sample criteria: Argentina, Brazil, Bulgaria, Chile, China, Colombia, Croatia, Ecuador, El Salvador, Hungary, Indonesia, Jamaica, Latvia, Lithuania, Malaysia, Mexico, Morocco, Pakistan, Panama, Peru, Philippines, Poland, Russia, South Africa, Thailand, Turkey, Ukraine, and Venezuela. The sample period ranges from 1994 to 2014. However, data on particular countries may start later or end earlier, depending on their data availability.

For all countries in the sample, we collect data on prices of sovereign debt and on output. Debt-price data consists of data on sovereign spreads of a synthetic basket of bonds of each country, computed by the EMBI. A bond spread is the excess yield of the bond over the yield of a risk-free zero-coupon bond (i.e., a US Treasury) of the same maturity. A country's spread is a synthetic measure of the spreads of a representative basket of bonds issued by that country. It measures the implicit interest rate premium required by investors to be willing to invest in a defaultable bond of that particular country. Spread data were obtained from Datastream.

Data on real GDP at a quarterly frequency was obtained from national sources and the IMF.

\section{Appendix C. Recursive Model Representation}

This section provides a recursive representation of the model of the global economy developed in Section 3. Within each period, the timing is as follows.

i. At the beginning of each period, the exogenous aggregate state, $\mathbf{s}_{x} \equiv\left\{z_{\mathrm{DM}}, y_{\mathrm{EM}}\right\}$, and the exogenous idiosyncratic state, $\left(z_{i}, \zeta_{i}\right)_{i \in[0,1]}$, are realized.

ii. Repayment stage. EM households choose repayment and DM firms choose production. The aggregate state in this stage is given by $\mathbf{s}_{-} \equiv\left\{\mathbf{s}_{x}, \Delta_{-}\right\}$, where $\Delta_{-} \equiv\left\{A_{\mathrm{DM}}, D, G_{-}(b, z)\right\}$, and $G_{-}(b, z)$ is the joint distribution of debt and idiosyncratic output at the repayment stage of EM economies that borrowed in the previous period.

iii. Borrowing stage. A random fraction $(1-\sigma)$ of global banks exit, and an equal mass of banks enter the economy. Global banks choose their portfolios, DM households their savings, nonfinancial firms production, and EM households their borrowing. The aggregate state at this stage is denoted by $\mathbf{s}_{+}=\left(\mathbf{s}_{x}, \Delta_{+}\right)$, where $\Delta_{+} \equiv\left\{N, G_{+}(b, z)\right\}, N$ is the 
aggregate net worth from global banks at the borrowing stage after entry and exit, and $G_{+}(b, z)$ is the joint distribution of debt and idiosyncratic output across EM borrowers that can borrow at the borrowing stage.

Global Banks' Recursive Problem. Denoting by $n$ the idiosyncratic net worth of a global bank at the borrowing stage, its recursive problem is given by

$$
\tilde{v}\left(n, \mathbf{s}_{+}\right)=\max _{\left\{a_{\mathrm{EM}(b, z)}^{\prime} \geq 0\right\}, a_{\mathrm{DM}}^{\prime} \geq 0, d^{\prime}, d \tilde{i} v \geq 0}(1-\sigma) n+\sigma\left[\tilde{d i v}+\beta_{\mathrm{DM}} \mathbb{E} \tilde{v}\left(n^{\prime}, \mathbf{s}_{+}^{\prime}\right)\right]
$$

subject to

$$
\begin{aligned}
n+d^{\prime} & =\iint_{(b, z): \mathrm{d} G_{+}(b, z)>0} a_{\mathrm{EM}(b, z)}^{\prime} \mathrm{d} b \mathrm{~d} z+a_{\mathrm{DM}}^{\prime}+\tilde{d i v}, \\
n & \geq \kappa\left(\iint_{(b, z): \mathrm{d} G_{+}(b, z)>0} a_{\mathrm{EM}(b, z)}^{\prime} \mathrm{d} b \mathrm{~d} z+a_{\mathrm{DM}}^{\prime}\right), \\
n^{\prime} & =\iint_{(b, z): \mathrm{d} G_{+}(b, z)>0} R_{\mathrm{EM}(b, z)}\left(\mathbf{s}_{+}, \mathbf{s}_{-}^{\prime}\right) a_{\mathrm{EM}(b, z)}^{\prime} \mathrm{d} b \mathrm{~d} z+R_{\mathrm{DM}}\left(\mathbf{s}_{-}^{\prime}\right) a_{\mathrm{DM}}^{\prime}-\beta_{\mathrm{DM}}^{-1} d^{\prime} \geq 0, \\
\mathbf{s}_{+}^{\prime} & =\Gamma_{+}\left(\mathbf{s}_{-}^{\prime}, \tilde{l}\left(\hat{b}, \hat{z}, \mathbf{s}_{-}^{\prime}\right)\right), \\
\mathbf{s}_{-}^{\prime} & =\Gamma_{-}\left(\mathbf{s}_{+}, \mathbf{s}_{x}^{\prime}, \tilde{A}_{\mathrm{DM}}\left(\mathbf{s}_{+}\right), \tilde{D}\left(\mathbf{s}_{+}\right), \tilde{b}\left(\hat{b}, \hat{z}, \mathbf{s}_{+}\right)\right),
\end{aligned}
$$

where div denotes dividend payments from banks that did not exit, $a_{\mathrm{EM}}^{\prime}(b, z)$ denotes the mass of securities purchased from a economies with borrowing $b$ and idiosyncratic income $z, a_{\mathrm{DM}}^{\prime}$ the mass of securities purchased from non-financial firms from DM economies, $R_{\mathrm{EM}(b, z)}\left(\mathbf{s}_{+}, \mathbf{s}_{-}^{\prime}\right)=$ $\frac{\mathbb{E}_{z^{\prime} \mid z} \iota\left(b^{\prime}\left(b, z, \mathbf{s}_{+}\right), z^{\prime}, \mathbf{s}_{-}^{\prime}\right)}{q\left(b, z, \mathbf{s}_{+}\right)}, R_{\mathrm{DM}}\left(\mathbf{s}_{-}^{\prime}\right)=z_{\mathrm{DM}}^{\prime} \alpha \tilde{A}_{\mathrm{DM}}\left(\mathbf{s}_{+}\right)^{\alpha-1}+(1-\delta)$, and $\tilde{A}_{\mathrm{DM}}($.$) denotes the perceived$ policies for aggregate DM assets at the borrowing stage described. The law of motion of the aggregate state, $\mathbf{s}_{+}$, from the repayment stage is given by $\mathbf{s}_{+}=\Gamma_{+}\left(\mathbf{s}_{-}, \tilde{\iota}\left(\hat{b}, \hat{z}, \mathbf{s}_{-}\right)\right)$, where $\tilde{\iota}\left(b, z, \mathbf{s}_{-}^{\prime}\right)$ is the borrower's perceived repayment policy. The law of motion of the aggregate state, $\mathbf{s}_{-}^{\prime}$, from the borrowing stage is given by $\mathbf{s}_{-}^{\prime}=\Gamma_{-}\left(\mathbf{s}_{+}, \mathbf{s}_{x}^{\prime}, \tilde{A}_{\mathrm{DM}}\left(\mathbf{s}_{+}\right), \tilde{D}\left(\mathbf{s}_{+}\right), \tilde{b}\left(\hat{b}, \hat{z}, \mathbf{s}_{+}\right)\right)$, and $\tilde{A}_{\mathrm{DM}}(),. \tilde{D}($.$) , and \tilde{b}^{\prime}($.$) denote perceived policies at the borrowing stage describing, respectively,$ aggregate DM assets, deposits, and EM borrowing. The laws of motion, $\Gamma_{+}($.$) and \Gamma_{-}($.$) , and$ perceived policies are equilibrium objects in the model, taken as given by global banks and EM borrowers. Note that this formulation uses the equilibrium deposit rate obtained from the DM households' problem, $R_{d t}=\beta_{\mathrm{DM}}^{-1}$. 
EMs' Recursive Problem. At the repayment stage, the borrower's repayment decision is characterized by the following problem.

$$
\begin{aligned}
V\left(b, z, \mathbf{s}_{-}\right) & =\max _{\iota} \iota V^{r}\left(b, z, \mathbf{s}_{+}\right)+(1-\iota) V^{d}\left(z, \mathbf{s}_{+}\right), \\
\mathbf{s}_{+} & =\Gamma_{+}\left(\mathbf{s}_{-}, \tilde{\iota}\left(\hat{b}, \hat{z}, \mathbf{s}_{-}\right)\right)
\end{aligned}
$$

where $V^{r}\left(b, z, \mathbf{s}_{+}\right)$and $V^{d}\left(z, \mathbf{s}_{+}\right)$denote, respectively, the values of repayment and default, described below.

At the borrowing stage, the borrower's debt-issuance decision is characterized by the problem

$$
\begin{aligned}
V^{r}\left(b, z, \mathbf{s}_{+}\right) & =\max _{b^{\prime}} u(c)+\beta \mathbb{E}\left[V\left(b^{\prime}, z^{\prime}, \mathbf{s}_{-}^{\prime}\right)\right] \\
\text { s.t. } c & =y_{\mathrm{EM}}+z+q\left(b^{\prime}, z, \mathbf{s}_{+}\right) b^{\prime}-b \\
\mathbf{s}_{-}^{\prime} & =\Gamma_{-}\left(\mathbf{s}_{+}, \mathbf{s}_{x}^{\prime}, \tilde{A}_{\mathrm{DM}}\left(\mathbf{s}_{+}\right), \tilde{D}\left(\mathbf{s}_{+}\right), \tilde{b}\left(\hat{b}, \hat{z}, \mathbf{s}_{+}\right)\right) .
\end{aligned}
$$

Finally, the value of default is given by

$$
\begin{aligned}
V^{d}\left(z, \mathbf{s}_{+}\right) & =\max _{b^{\prime}} u(c)+\beta \mathbb{E}\left[\phi V^{r}\left(0, z^{\prime}, \mathbf{s}_{+}^{\prime}\right)+(1-\phi) V^{d}\left(z^{\prime}, \mathbf{s}_{+}^{\prime}\right)\right] \\
\text { s.t. } c & =\mathcal{H}\left(y_{\mathrm{EM}}+z\right), \\
\mathbf{s}_{+}^{\prime} & =\Gamma_{+}\left(\mathbf{s}_{-}^{\prime}, \tilde{\iota}\left(\hat{b}, \hat{z}, \mathbf{s}_{-}^{\prime}\right)\right), \\
\mathbf{s}_{-}^{\prime} & =\Gamma_{-}\left(\mathbf{s}_{+}, \mathbf{s}_{x}^{\prime}, \tilde{A_{\mathrm{DM}}}\left(\mathbf{s}_{+}\right), \tilde{D}\left(\mathbf{s}_{+}\right), \tilde{b^{\prime}}\left(\hat{b}, \hat{z}, \mathbf{s}_{+}\right)\right) .
\end{aligned}
$$

Equilibrium Definition. We can now define a recursive equilibrium.

Definition 2. A recursive equilibrium consists of global banks' policies, $\left\{a_{\mathrm{EM}(b, z)}^{\prime}\left(n, \mathbf{s}_{+}^{\prime}\right), a_{\mathrm{DM}}^{\prime}\left(n, \mathbf{s}_{+}^{\prime}\right)\right.$, $\left.d_{\mathrm{DM}}^{\prime}\left(n, \mathbf{s}_{+}^{\prime}\right)\right\}$, and value function, $\tilde{v}\left(n, \mathbf{s}_{+}^{\prime}\right)$; borrowers' policies, $\left\{\iota\left(b, z, \mathbf{s}_{-}^{\prime}\right), b^{\prime}\left(b, z, \mathbf{s}_{+}^{\prime}\right)\right\}$, and value functions, $\left\{V\left(b, z, \mathbf{s}_{-}\right), V^{r}\left(b, z, \mathbf{s}_{+}\right), V^{d}\left(z, \mathbf{s}_{+}\right)\right\}$; price schedules, $q\left(b^{\prime}, z, \mathbf{s}_{+}\right)$; laws of motion of aggregate states, $\Gamma_{+}\left(\mathbf{s}_{-}^{\prime}, \tilde{\iota}\left(\hat{b}, \hat{z}, \mathbf{s}_{-}^{\prime}\right)\right), \Gamma_{-}\left(\mathbf{s}_{+}, \mathbf{s}_{x}^{\prime}, \tilde{A}_{\mathrm{DM}}^{\prime}\left(\mathbf{s}_{+}\right), \tilde{D}^{\prime}\left(\mathbf{s}_{+}\right), \tilde{b}^{\prime}\left(b, z, \mathbf{s}_{+}\right)\right)$; and perceived policies, $\left\{\tilde{\iota}\left(b, z, \mathbf{s}_{-}^{\prime}\right), \tilde{b}^{\prime}\left(b, z, \mathbf{s}_{+}\right), \tilde{A}_{\mathrm{DM}}^{\prime}\left(\mathbf{s}_{+}\right), \tilde{D}^{\prime}\left(\mathbf{s}_{+}\right)\right\}$such that

(1) Given prices, laws of motion, and perceived policies, global banks' policies and value function solve their recursive problem (18).

(2) Given prices, laws of motion, and perceived policies, borrowers' policies and value functions solve their recursive problem (19)-(22).

(3) Asset markets clear.

(4) The laws of motion of the aggregate state are consistent with individual policies.

(5) Perceived policies coincide with optimal policies. 


\section{Appendix D. Solution Method}

As discussed in Appendix C, our model agents' heterogeneity and aggregate uncertainty imply that the distribution of assets in the world economy, $\Delta$, an infinite-dimensional object, is a state variable in agents' individual problems. To solve for the equilibrium of the model numerically, we follow a common practice in existing algorithms and use as state variables a set of statistics that summarize this distribution (see Algan et al., 2014, for a review of algorithms to solve models with heterogeneous agents and aggregate uncertainty).

The detailed choices in our solution method are guided by three particular features of our model. First, individual EMs' problems involves a default choice without commitment, which requires the use of global methods in the solutions of these problems. Second, with default risk, the degree of aggregate uncertainty in the economy significantly affects the debt-price schedules EMs face, as well as their policy functions. Therefore, we choose a method that uses the statistics summarizing the aggregate distribution as part of the state variables in the agents' individual problems. ${ }^{6}$ The curse of dimensionality in the solution of these problems then naturally limits the dimension of the vector of states summarizing the distribution of assets. Finally, in our economy, the debt-price schedules individual EMs face depend on the perceived policy of banks' DM-firm-invested assets, $\tilde{A}_{\mathrm{DM}}\left(\mathbf{s}_{+}\right)$, which governs DM firms' marginal product of capital. In equilibrium, perceived policies, in turn, must coincide with actual policies. To avoid inaccuracies originated in this perceived policy function, we instead choose an auxiliary aggregate variable $\hat{A}_{\mathrm{DM}}$, describing aggregate investment in DM firms at the end of the period, as a state variable in agents' individual problems. Using $\hat{A}_{\mathrm{DM}}$ as a state also has the advantage that the approximate solution is always consistent with market clearing.

From these considerations, our approximate solution considers the following problems for individual agents. For global banks, we express their recursive problem as

$$
\begin{aligned}
v\left(s_{x}, \hat{A}_{\mathrm{DM}}, m\right) & =(1-\sigma)+\sigma \beta_{\mathrm{DM}} \frac{1}{\kappa} \mathbb{E} v\left(s_{x}^{\prime}, \hat{A}_{\mathrm{DM}}^{\prime}, m^{\prime}\right)\left[\mathcal{R}_{\mathrm{DM}}\left(z_{\mathrm{DM}}^{\prime}, \hat{A}_{\mathrm{DM}}^{\prime}\right)-R_{d}(1-\kappa)\right] \\
\text { s.t. } & \mathcal{R}_{\mathrm{DM}}\left(z_{\mathrm{DM}}^{\prime}, \hat{A}_{\mathrm{DM}}^{\prime}\right)=z_{\mathrm{DM}}^{\prime} \alpha\left(\hat{A}_{\mathrm{DM}}^{\prime}\right)^{\alpha-1}+(1-\delta), \\
& \hat{A}_{\mathrm{DM}}^{\prime}=\mathcal{F}_{A}\left(s_{x}, \hat{A}_{\mathrm{DM}}, m\right) \\
& m^{\prime}=\mathcal{F}_{m}\left(s_{x}, \hat{A}_{\mathrm{DM}}, m\right)
\end{aligned}
$$

\footnotetext{
${ }^{6}$ The relevance of the degree of aggregate uncertainty in our model makes us depart from an algorithms that involves perturbation methods around a solution of the model with no aggregate uncertainty (e.g., Reiter, 2009), which have typical computational speed and allow for a large set of state variables.
} 
where $\mathcal{F}_{A}($.$) and \mathcal{F}_{m}($.$) denote forecasting rules assumed to be used by agents under the approx-$ imate solution, and $m$ is a set of moments describing the distribution $\Delta$. Note that once the variable $\hat{A}_{\mathrm{DM}}$ is included as a state, the statistics summarizing the distribution $\Delta$ only matter for forecasting $\hat{A}_{\mathrm{DM}}^{\prime}$.

For individual EMs, their repayment decision under our approximate solution is characterized by

$$
V\left(b, z, s_{x}, \hat{A}_{\mathrm{DM}}, m\right)=\max _{\iota} \iota V^{r}\left(b, z, s_{x}, \hat{A}_{\mathrm{DM}}, m\right)+(1-\iota) V^{d}\left(z, s_{x}, \hat{A}_{\mathrm{DM}}, m\right),
$$

where $V^{r}\left(b, z, s_{x}, \hat{A}_{\mathrm{DM}}, m\right)$ denotes the value of repayment described by

$$
\begin{aligned}
V^{r}\left(b, z, s_{x}, \hat{A}_{\mathrm{DM}}, m\right) & =\max _{b^{\prime}} u(c)+\beta \mathbb{E}\left[V\left(b^{\prime}, z^{\prime}, s_{x}^{\prime}, \hat{A}_{\mathrm{DM}}^{\prime}, m^{\prime}\right)\right], \\
\text { s.t. } c & =y_{\mathrm{EM}}+z+q\left(b^{\prime}, z, s_{x}, \hat{A}_{\mathrm{DM}}, m\right) b^{\prime}-b,(25),(26), \\
q\left(b^{\prime}, z, s_{x}, \hat{A}_{\mathrm{DM}}, m\right) & =\frac{\mathbb{E}\left[v\left(s_{x}^{\prime}, \hat{A}_{\mathrm{DM}}^{\prime}, m^{\prime}\right) \tilde{\iota}\left(b^{\prime}, z^{\prime}, s_{x}^{\prime}, \hat{A}_{\mathrm{DM}}^{\prime}, m^{\prime}\right)\right]}{\mathbb{E}\left[v\left(s_{x}^{\prime}, \hat{A}_{\mathrm{DM}}^{\prime}, m^{\prime}\right) \mathcal{R}_{\mathrm{DM}}\left(z_{\mathrm{DM}}^{\prime}, \hat{A}_{\mathrm{DM}}^{\prime}\right)\right]}
\end{aligned}
$$

and $V^{d}\left(z, s_{x}, \hat{A}_{\mathrm{DM}}, m\right)$, the value of default, is given by

$$
\begin{aligned}
V^{d}\left(z, s_{x}, \hat{A}_{\mathrm{DM}}, m\right) & =\max _{b^{\prime}} u(c)+\beta \mathbb{E}\left[\phi V^{r}\left(0, z^{\prime} s_{x}^{\prime}, \hat{A}_{\mathrm{DM}}^{\prime}, m^{\prime}\right)+(1-\phi) V^{d}\left(z^{\prime}, s_{x}^{\prime}, \hat{A}_{\mathrm{DM}}^{\prime}, m^{\prime}\right)\right], \\
\text { s.t. } c & =\mathcal{H}\left(y_{\mathrm{EM}}+z\right),(25),(26) .
\end{aligned}
$$

For the forecasting rules, our benchmark algorithm follows Krusell and Smith (1998) in parameterizing an assumed functional form for the rule and using an iterative procedure with model-simulated data to estimate the parameters of the functional form. ${ }^{7}$ To make the procedure parsimonious, we assume a log-linear forecasting rule in the state variables and summarize the distribution of borrowing across EMs with the mean of the distribution. ${ }^{8}$ Our algorithm then proceeds as follows:

(1) Specify initial forecasting rules, denoted $\mathcal{F}_{A}^{j}($.$) and \mathcal{F}_{m}^{j}($.$) for j=0$.

(2) Solve individual agents' problems given the forecasting rules $\mathcal{F}_{A}^{j}($.$) and \mathcal{F}_{m}^{j}($.$) for j=0$, using value function iteration.

(3) Simulate data from the model using the policy functions obtained in (2) for a given sequence of exogenous variables, $\tilde{s}_{x} \equiv\left\{s_{x, t}\right\}_{t=1}^{T}$, where $T$ is the time length of the panel

\footnotetext{
${ }^{7}$ We are currently working on a version of our algorithm using parametrized cross-sectional distributions as in Algan et al. (2010).

${ }^{8}$ Considering richer forecasting rules lead to convergence problems in the iterative procedure's rule.
} 
of model-simulated data. Estimate the parameters of the forecasting rule with modelsimulated data and denote the new forecasting rules $\mathcal{F}_{A}^{j+1}($.$) and \mathcal{F}_{m}^{j+1}($.$) . Denoting by$ $\mathcal{F}^{j}\left(\tilde{s}_{x}\right)$ the sequence of forecasts under the rules $\mathcal{F}_{A}^{j}($.$) and \mathcal{F}_{m}^{j}($.$) for the sequence \tilde{s}_{x}$, compute the distance $\delta_{j+1} \equiv\left\|\tilde{\mathcal{F}}^{j+1}\left(\tilde{s}_{x}\right)-\tilde{\mathcal{F}}^{j}\left(\tilde{s}_{x}\right)\right\|$.

(4) Update forecast rules and iterate in steps (2) and (3) for $j=1,2,3, \ldots$, until $\delta_{j+1}$ is sufficiently small. 